\section{A REVIEW OF HEAT TRANSFER IN TURBOCHARGERS}

A. Romagnoli, A. Manivannan, Nanyang Technological University, Angapore

S. Rajoo*, M.S. Chiong, UTM Centre for Low Carbon Transport (Locartic), Universiti Teknologi Malaysia

A. Feneley, A. Pesiridis, Brunel University, United Kingdom

R.F. Martinez-Botas, Department of Mechanical Engineering, Imperial College London, United Kingdom.

\section{ABSTRACT}

The conventional powertrain has seen a continuous wave of energy optimization, focusing heavily on boosting and engine downsizing. This trend is pushing OEMs to consider turbocharging as a premium solution for exhaust energy recovery. Turbocharger is an established, economically viable solution which recovers waste energy from the exhaust gasses, and in the process providing higher pressure and mass of air to the engine. However, a turbocharger has to be carefully matched to the engine. The process of matching a turbocharger to an engine is implemented in the early stages of design, through air system simulations. In these simulations, a turbocharger component is represented largely by performance maps and it serves as a boundary condition to the engine. The thermodynamic parameters of a turbocharger are calculated through the performance maps which are usually generated experimentally in gas test stands and used as look-up table in the engine models. Thus, the operational of the engine is dictated by the air flow thermodynamic parameters (pressure, temperature and mass flow) from the turbocharger compressor; this in turn will determine the thermodynamic parameters for the exhaust gas entering the turbocharger turbine. The importance and its sensitivity dictate that any heat transfer affecting the experiments to acquire the performance maps will cause errors in the characterization of a turbocharger. This will consequently lead to inaccurate predictions from the engine model if the heat transfer effects are not properly accounted for. The current paper provides a comprehensive review on how the industry and academics are addressing the heat transfer issue through advancing researches. The review begins by defining the main issues related with heat transfer in turbochargers and the stateof-the-art research looking into it. The paper also provides some inputs and recommendations on the research areas which should be further investigated in the years to come.

\section{INTRODUCTION}

The biggest challenge faced by the global automotive industry is meeting the emission regulations and standards for exhaust gases such as Carbon Dioxide, Nitrous Oxide and Particulate Material from automobiles. Another challenge is the increasing demand for fuel-efficient vehicles from consumers as well as governments. These challenges have led OEMs and component manufacturers to invest their resources in developing technologies which can help the automobiles to comply with the various government regulations in different regions.
Turbochargers offer the benefits of both, improved fuel economy and reduction in emissions. The scenario which is prevailing in the global automotive industry has fueled the adoption of turbochargers across all the vehicle segments. Turbochargers utilize the exhaust gases from the engine to compress the atmospheric air and feed it back to the engine. This generates a better combustion and provides a boost for the vehicle. This has enabled the OEMs to downsize their engines without sacrificing the performance and also improving fuel efficiency of the vehicle. The adoption of turbocharger in diesel engines is comparatively higher than gasoline. However, the penetration of gasoline turbocharger is estimated to increase at a double digit rate in the near future. The turbochargers, apart from the automotive application, are also prevalent in areas as marine, stationary power plants, other stationary gensets, and off-highway vehicles.

Turbocharger development has experienced a significant improvement in research activities over the last decades. Even though aerodynamic optimization of turbines and compressors accounts for the largest portion of these research activities, it can no longer be done in isolation. The need for compact, lightweight and high performance engines requires integrating turbocharger development as part of the engine development itself; this particularly includes engine-turbocharger matching which is a crucial step in the preliminary design phase of an engine. One of the main areas affecting engine-turbochargers matching is the evaluation and assessment of heat transfer within the turbocharger. In fact it is generally agreed that the turbocharger cannot be considered adiabatic and heat transfer effects had to be included to fully understand its operating range. It is now accepted knowledge that when turbochargers are treated as diabatic machines (i.e. non-adiabatic), its rated efficiency is lower than the conventional adiabatic assumption (a more detailed description and quantification will be provided in the next paragraphs).

Rautenberg et al. [1] is one of the first researchers who raised the argument on the detrimental effect of heat transfer process in the turbocharger performance prediction. The consequences of heat transfer are shown through aerodynamic and thermodynamic effects. The aerodynamic effect is noticed as the change in velocity triangle and fluid properties (such as Reynolds number, viscosity, density) while the change in work/power of the turbocharger components denotes the thermodynamic effect. Heat transfer effects could be significant, which results in inaccurate measurements and prediction of turbocharger performance and flow properties. The heat transfer within the turbocharger changes the temperatures at the inlet and outlet of compressor and turbine. An increase in inlet temperature of the compressor will require an incremental work to produce the same pressure ratio. If the compressor outlet temperature is high, inter-coolers must be employed to condition the compressed air before it enters the engine. A drop in the temperature at turbine outlet due to heat loss, may be wrongly accounted as higher enthalpy drop thus leading to erroneous performance measurement and prediction. The prediction of turbocharger outlet properties such as the compressor outlet and turbine outlet temperatures [2] is critical in the development of 
air handling units such as intercoolers, exhaust energy recovery systems, after treatment devices and two-stage turbochargers. Furthermore, an inaccurate performance map will affect the turbocharger-engine matching. Turbocharger-engine simulation can be improved with the addition of heat transfer effects, leading to better predictions of engine parameters. Accurate prediction of engine performance is thus based on the complete knowledge of the turbocharger performance inclusive its heat transfer phenomenon.

This review paper, which targets radial turbomachinery and internal combustion engine professionals, aims to provide a complete overview of heat transfer in turbochargers. The review begins with a problem statement before moving through structured sections on thermodynamic analysis, a description of turbocharger heat fluxes, experimental and analytical methods to characterize turbocharger performance, a review of current research, and closing with a description of the state of the art, future trends and conclusions.

\section{PROBLEM STATEMENT}

Although the working principle of turbocharger is relatively simple, a short description is given as follows (refer to Figure 1). A turbocharger is made up of two sections - turbine and compressor. The turbine consists of a housing which collects and guides the exhaust gas into the wheel. The flow momentum changes through the turbine wheel results in spinning and work extraction. Similarly, the compressor also consists of wheel and housing. The compressor wheel is connected to the turbine via a shaft which is housed in an intermediate body called the bearing housing. The turbine extracts energy from the exhaust gas, which converted into shaft power used to spin the compressor wheel. As the wheel spins, air is drawn through the compressor which raises its pressure higher than ambient. The compressed air is then pushed into the engine, thus allowing the engine to burn more fuel and produce more power.

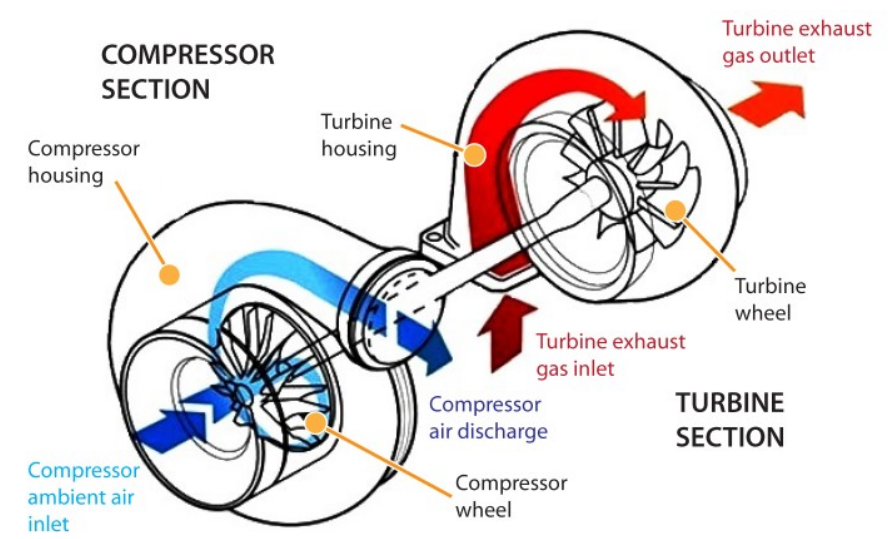

Figure 1: Turbocharger layout

As one can imagine, due to the compact nature of a turbocharger and the large temperature of the exhaust gas (in gasoline engines this can be greater than $1000 \mathrm{~K}$ ), there is a significant amount of heat transfer between the turbine and the compressor which might affect the engine-turbocharger matching.
The matching of a turbocharger with an internal combustion engine is a crucial step in the development process and relies on simulation of the engine air path system. In these models, turbochargers are represented by characteristic maps, which are defined from gas stand measurements of pressure ratio, shaft speed, mass flow and isentropic efficiency. Whilst the mass flow, pressure ratio, and speed can be measured directly, the efficiency has to be calculated from the measured gas temperatures. For both turbine and compressor, enthalpy changes in the working fluids are equated to work changes during the characterization process. Any heat transfer affecting these gas temperature measurements will cause errors in the characterization process. Conversely, when the characteristic maps are subsequently used in engine simulations to predict engine performance; if heat transfers are ignored then a poor prediction of gas temperatures for inter-cooling and aftertreatment will arise. Consequently there is a twofold interest in understanding and modelling heat transfer in turbochargers:

1. To improve the accuracy of work transfer measurements during characterization.

2. To improve the prediction of gas temperatures in engine simulations.

This article will review the past and current research to highlight the direction towards which R\&D should be heading in order to redefine turbochargers as diabatic machines. The article will initially go through a thermodynamic analysis of the heat transfer process in turbochargers; it will then outline more in detail current techniques/methodologies used for heat transfer studies in turbochargers (experiments, 3-D/1-D simulation) followed by reviewing the most relevant work done in the following specific areas:

- Correction of compressor/turbine performance maps under diabatic conditions;

- Improve methods to predict performance under diabatic conditions;

- Quantification of diabatic and adiabatic efficiency in turbochargers;

- Actual work/power;

- Heat flux in turbocharger components;

- Parameters affecting heat transfer;

- On-engine effect;

- Transient analysis;

Finally the article will provide an insight on future perspectives and challenges for heat transfer research in turbochargers. 


\section{THERMODYNAMIC ANALYSIS OF HEAT TRANSFER IN TURBOCHARGERS}

The importance of assessing heat transfer in turbochargers is mainly driven by the need for accurate determination of the enthalpy content in the working fluids. However it should be noted that heat transfer in turbochargers is a very complex phenomenon which occurs in a three-dimensional domain and it is strongly affected by the turbocharger configurations (e.g. size, cooling method and materials) and by the surrounding environment at which they are exposed to (e.g. proximity of the engine, packaging, engine size and operating conditions). This is particularly true in the compressor and turbine for which heat transferred in/out of the working fluid depends not just on the configuration and surrounding environment, but also on the compression/expansion process which leads to temperature change as a consequence of the pressure change. This can be explained by looking at the entropy of a gas between two states, shown in Eq. (1),

$S_{2}-S_{1}=c_{p} \ln \left(\frac{T_{2}}{T_{1}}\right)-R \ln \left(\frac{P_{2}}{P_{1}}\right)$

By substituting the state equation of gas $(P V=\rho R T)$ in Eq. 1 and by rearranging between the terms on the right and left hand-side, one would obtain the correlation in Eq. (2),

$\frac{T_{2}}{T_{1}}=\left(\frac{P_{2}}{P_{1}}\right)^{\gamma-1 / \gamma}$

Equation (2) shows the effect of pressure on temperature. As seen in Figure 2, during compression as the pressure increases from $P_{1}$ to $P_{2}$, the temperature increases from $T_{1}$ to $T_{2}$ according to the Equation 2, and the exponent $\gamma$ depends on the type of gas being considered ${ }^{1}$.

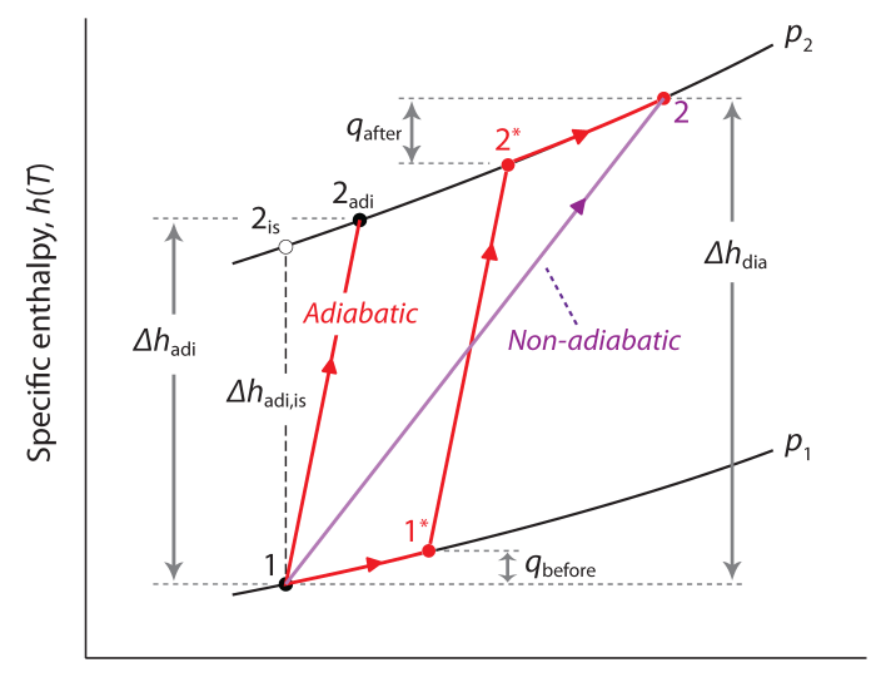

Specific entropy, $s(p, T)$

Figure 2: Compressor h-S diagram

\footnotetext{
${ }^{1}$ The proposed example refers to a compression process. However same explanation is valid for the expansion process within a turbine; the only difference is that exponential term of Equation 2 would be inverted.
}

Heat addition and heat removal is a continuous process and any attempt to describe it by means of discrete heat additions/removals holds several assumptions and simplifications which are far from being representative of the real process. However an h-S diagram represents a good starting point to provide a qualitative and quantitative assessment of the heat transfer within a turbocharger. In fact a $h$-S diagram allows one to visualize the different stages of heat addition and removal as well as to quantify it by means of calculation of enthalpy rise or drop respectively. In Figure 2 it is given an h-S diagram for a compression process between pressures $P_{1}$ and $P_{2}$. If the compression was adiabatic, the final state of the working fluid would be given by point $2_{\text {adi }}$. However if heat addition was present, the final state of the working fluid would be different. The final temperature would no longer be $2_{\text {adi }}$ but it would be equal to 2. The diabatic nature of the compression process can thus be illustrated from stage $1 \rightarrow 2$ as shown in the Figure 2 . The stages in which heat addition or removal takes place depends on the assumptions made by researchers. The compression process within the compressor wheel is generally assumed to be adiabatic but some researchers consider heat addition to occur before and after compression process. However there are others who assume no heat addition occurring before the compression (all the heat addition is said to take place after the compression). The former can be described by the process path $1 \rightarrow 1^{*} \rightarrow 2^{*}$ adi $\rightarrow 2$ : heat addition before compression leads to temperature rise along the constant pressure curve $P_{l}$, from $1 \rightarrow 1^{*}$, the adiabatic compression process then goes through stage $1^{*} \rightarrow 2^{*}$ adi and finally heat addition after compression is represented by stage path $2 *{ }_{\text {adi }} \rightarrow 2$ along the constant pressure curve $P_{2}$. The latter instead is described by the process path $1 \rightarrow 2_{\text {adi }} \rightarrow 2$. The main advantage of splitting the heat transfer process in well-defined distinct processes is that it is possible to easily quantify heat addition and removal as enthalpy difference, ( $\mathrm{q}_{\text {before }}$ and $\left.\mathrm{q}_{\text {after }}\right)$ and therefore evaluate the so-called diabatic efficiency. Eq. (3),

The general static to static compressor efficiency is given by

$$
\eta=\frac{\int_{1}^{x} v d p}{w_{t, 12}}
$$

where the numerator is the specific flow work and the denominator is the actual specific shaft work. The integration path taken from stage 1 to $\mathrm{x}$ defines the type of thermodynamic process - isothermal, isentropic or polytropic [3]. In turbomachinery performance estimation, the numerator (i.e. $h_{2, i s}-h_{1}=\int_{1}^{2, i s} v d p$ ) describes an isentropic process for a perfect adiabatic machine with no entropy change and dissipation loss whereas the denominator denotes the shaft work equal to the change in actual enthalpy. This is not the case when heat transfer is present, due to its contribution to the change in the fluid enthalpy.

The traditional definition of adiabatic efficiency is given in Eq. (4), 
$\eta_{\text {adi }, C}=\frac{\Delta h_{\text {adi } i s}}{\Delta h_{\text {adi }}}=\frac{T_{2, i s}-T_{1}}{T_{2, a d i}-T_{1}}$

In order to take into account of the heat transfer process within the compressor, the diabatic efficiency is calculated as in Eq. (5),

$\eta_{\text {dia }, C}=\frac{\Delta h_{a d i, i s}}{\Delta h_{\text {dia }}}=\frac{T_{2, i s}-T_{1}}{T_{2}-T_{1}}$

Since $T_{2}$ is greater than $T_{2, \text { adi }}$, the compressor diabatic efficiency is smaller its adiabatic efficiency.

On the turbine side, the expansion process can similarly be divided into three stages (refer to Figure 3). To account for heat transfer, the general assumption is that the heat removal occurs before and after the expansion process, while the expansion itself is adiabatic ${ }^{2}$. This is shown in Figure 3 by the process path $3 \rightarrow 3^{*} \rightarrow 4^{*} \rightarrow 4$. Heat removal before the expansion occurs through the constant pressure curve $P_{3}$ from $3 \rightarrow 3^{*}$. The adiabatic expansion process goes through stage $3^{*} \rightarrow 4^{*}$ and finally heat is removed after the expansion through the constant pressure curve $P_{4}$, from $4 * \rightarrow 4^{*}$ dia.

The turbine adiabatic efficiency is defined as in Eq. (6),

$$
\eta_{a d i, T}=\frac{\Delta h_{a d i}}{\Delta h_{a d i, i s}}=\frac{T_{3}-T_{4, a d i}}{T_{3}-T_{4, i s}}
$$

In order to take into account for the heat transfer process within the turbine, the diabatic efficiency is calculated as in Eq. (7),

$$
\eta_{\text {dia }, T}=\frac{\Delta h_{\text {dia }}}{\Delta h_{\text {adi, } i s}}=\frac{T_{3}-T_{4}}{T_{3}-T_{4, i s}}
$$

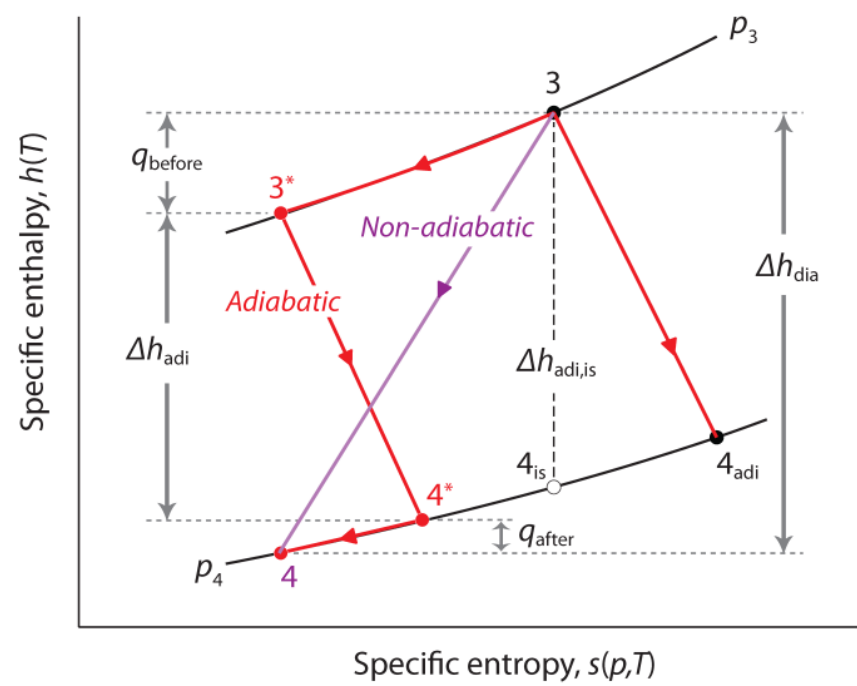

Figure 3: Turbine h-S diagram

\footnotetext{
${ }^{2}$ Unlike the compressor case, heat added after the expansion can be considered as negligible.
}

Since $T_{4}$ is smaller than $T_{4, \text { adi }}$, the turbine diabatic efficiency is higher than its adiabatic efficiency. It is worth noting that under diabatic conditions, due to the large heat fraction before the expansion, the expansion shifts towards lower entropies than the isentropic case. This causes the non-adiabatic efficiency to be greater than unity since $\Delta \mathrm{h}_{\mathrm{dia}}>\Delta \mathrm{h}_{\mathrm{adi}, \mathrm{is}}$. Obviously this is not physically possible and it comes as a consequence of the fact that the diabatic efficiency, as defined in Eq. (7), does not take into account the work done against the mechanical friction losses. In order to accurately evaluate the turbine diabatic efficiency, the shaft power should be directly measured on the turbine itself.

\section{HEAT FLUXES IN TURBOCHARGERS}

In order to get more insight about the heat transfer process in compressor and turbine, it is worth looking at the heat transfer mechanism of conduction, convection \& radiation. Figure 4 shows the longitudinal section of a simplified turbocharger model together with its main heat transfer paths. The exhaust gases coming from the combustion flow into the turbine, exchange heat by forced convection to the turbine casing and to the bearing housing $\left(Q_{t / B H}\right)$. Due to the temperature gradient between the inner and outer surface of the turbine casing, heat is conducted through the wall and dissipated by radiation $\left(Q_{t, \text { rad }}\right)$ and free convection $\left(Q_{t, c o n v}\right)$ to the surrounding environment. At the same time, the air that flows through the rotor expands and, as a consequence the pressure drops, the temperature decreases. In this process, heat is transferred to the blades and subsequently to the shaft. The turbine exit temperature is therefore calculated as the sum of the temperature drop due to the expansion and the heat transferred to the shaft $(Q t / S)$. In the bearing housing the heat is dissipated by forced convection to the oil $\left(\mathrm{Q}_{o i l / B H}\right)$, and through free convection $\left(Q_{B H, \text { conv }}\right)$ and radiation $\left(\mathrm{Q}_{B H, r a d}\right)$ to the environment. In the shaft, the heat is dissipated only by forced convection to the oil $\left(Q_{S / / o i l}\right)$. Note that the heat generated by friction within the bearing housing is not considered here.

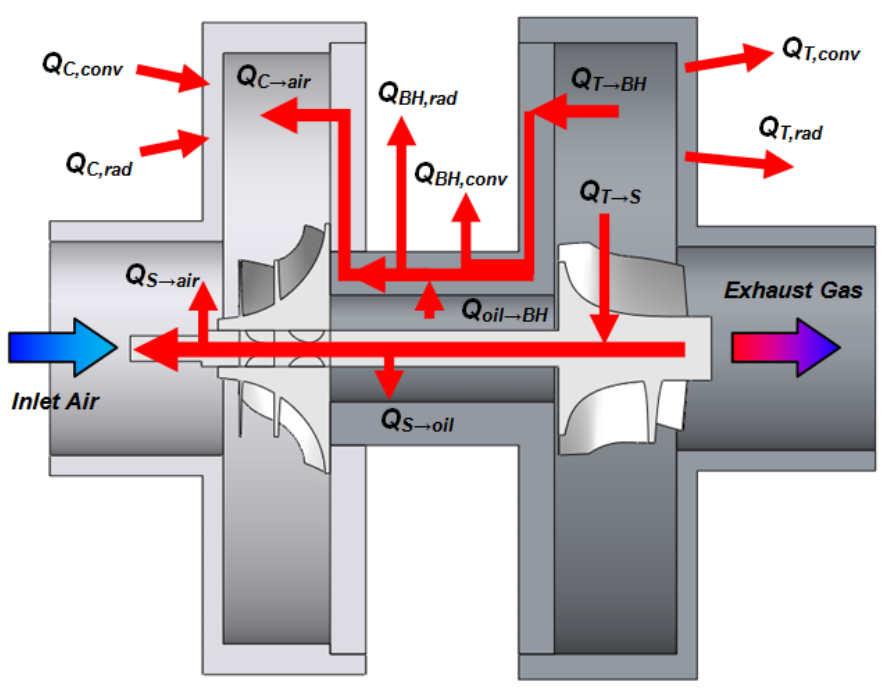

Figure 4: Reduced order heat transfer model [4] 


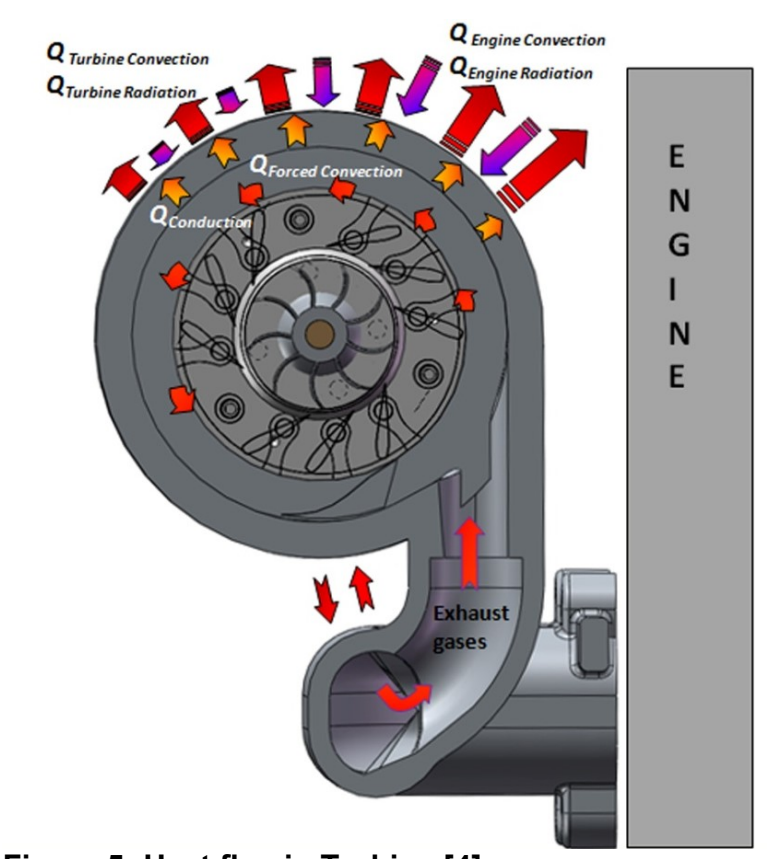

Figure 5: Heat flux in Turbine [4]

While the gases expand in the turbine, cold air flows into the compressor. The inlet air is heated up by the shaft $\left(Q_{S / a i r}\right)$ and compressed $\mathrm{i} n$ the impeller with a consequent rise in temperature and pressure. After the compression, the air flows into the diffuser, where the gas is further heated by forced convection from the back-plate $\left(Q_{c / a i r}\right)$, natural convection $\left(Q_{c, \text { conv }}\right)$ and radiation $\left(Q_{c, \text { rad }}\right)[4]$.

A simplified schematic diagram of the heat transfer process occurring within the turbine and the compressor casing is given in Figures 5 and 6 . The high temperature of the turbine casing causes the heat fluxes to be directed towards the surrounding environment while the opposite occurs on the compressor side.

Before moving forward, some remarks about the heat transfer processes described so far are required:

1- The compressor casing is externally heated by the heat conducted through the bearing housing from the turbine and the heat radiated from the turbine housing and the engine. As already described before, the heat fluxes are usually pointing inwards (i.e. heat from the compressor casing is transferred to the compressed air). However at high rotational speeds and pressure ratios, the temperature of the compressed air tends to increase substantially (refer to Eq. (2)) and therefore the temperature difference between the compressed air and the casing tends to decrease and in some cases to become negative (i.e., the compressed air temperature is larger than the compressor casing, hence the heat flux will be pointing outwards). Under this condition, the compressor casing lowers its temperature by radiating heat to the environment. In addition to this, the compressor casing also conducts heat to the bearing housing, where oil or liquid coolant absorbs the heat. This is shown in Figure 7 and reported by Shaaban and J.Seume [5].

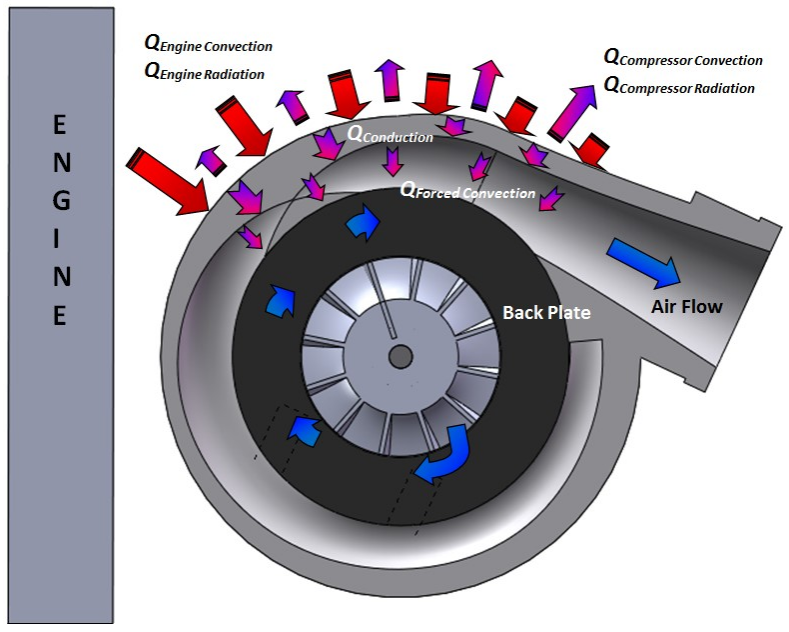

Figure 6: Heat flux in compressor [4]

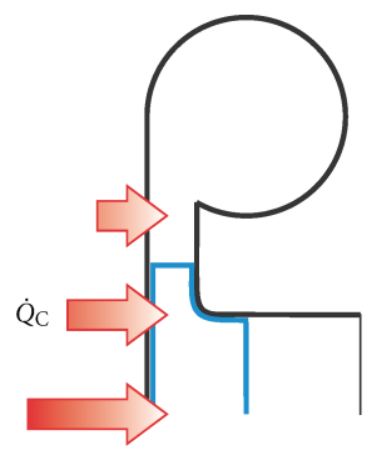

Low rotational speed

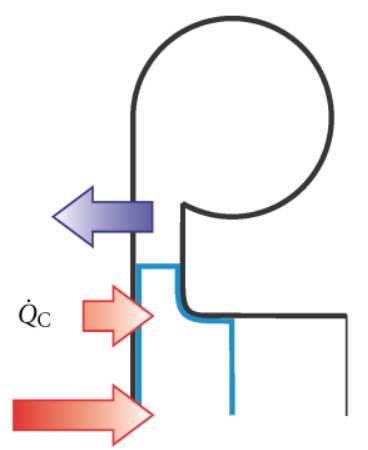

High rotational speed
Figure 7: Modes of thermal energy transfer to the compressor [5]

2- The exhaust gas from the engine carries energy in the form of kinetics, pressure and heat. Some part of the pressure and kinetic energy is extracted by the turbine to drive the compressor, whereas part of the heat energy is absorbed by the turbine inlet walls. The turbine housing radiates heat to the environment and this heat loss could represent a major portion of the total enthalpy in the turbine. However, as the exhaust gas temperature increases, the turbine work increases and diminishes the importance of heat loss relative to the turbine work. This does not mean the heat transfer is reduced in its magnitude.

3- The bearing housing acts as a thermal buffer between the turbine and compressor. Nevertheless heat transfer does take place between these components.

4- Depending on the type of measurements (either hot or cold measurements) being carried out to assess the performance of turbine and compressor, diabatic or adiabatic performance maps will be generated. The difference between these efficiency terms can be significant (more than $30 \%$ in some cases), leading to erroneous results during engine turbocharger-matching. As further remarks, it is worth noting that under real operating conditions, a turbocharger will always be operating under diabatic conditions, hence the importance to address the heat transfer issues in turbochargers. 
5 METHODS FOR MEASURING \& MODELLING HEAT TRANFER IN TURBOCHARGERS

\subsection{Experimental Measurements}

Early efforts of using experimental tests to investigate heat transfer in turbochargers were undertaken by Rautenberg et al. [1] and similarly by Malobabic and Rautenberg [6] in the 1980s. These initial investigations focused on the comparison of hot and cold flow test results, where the cold test was assumed to be adiabatic.

Turbocharger performance maps are generated by different measurement techniques - commonly known as hot and cold measurements:

Hot measurements are the standard practice of turbocharger manufacturers to generate performance maps (diabatic maps) that include heat transfer and mechanical losses. In hot measurements two options are available - the first consists of insulating the entire turbocharger in order to quantify the internal heat fluxes; the second option is to let the turbocharger exposed to the ambient environment in order to quantify the impact of external heat flux. The latter is the most practiced option amongst turbocharger manufacturers.

Hot measurements are usually carried out in hot gas test stands in which electrically heated compressed air $[8,7,9$,] or a burner $[5,9]$ is used to generate hot gas to drive the turbine (refer to Figure 8). The Turbine Inlet Temperature (TIT) is controlled by adjusting the fuel flow rate [5]. The turbine outlet gas is sometimes cooled by heat exchanger for accurate measurement of mass flow. The operating point of the compressor is controlled by a back pressure valve at the compressor outlet [ 7 , $8,10,11,12,13]$. The hot measurements for the compressor and turbine are recommended to be done simultaneously when generating the performance maps, to properly account for the heat transfer effects whose direction depends on the operating point of the turbocharger.

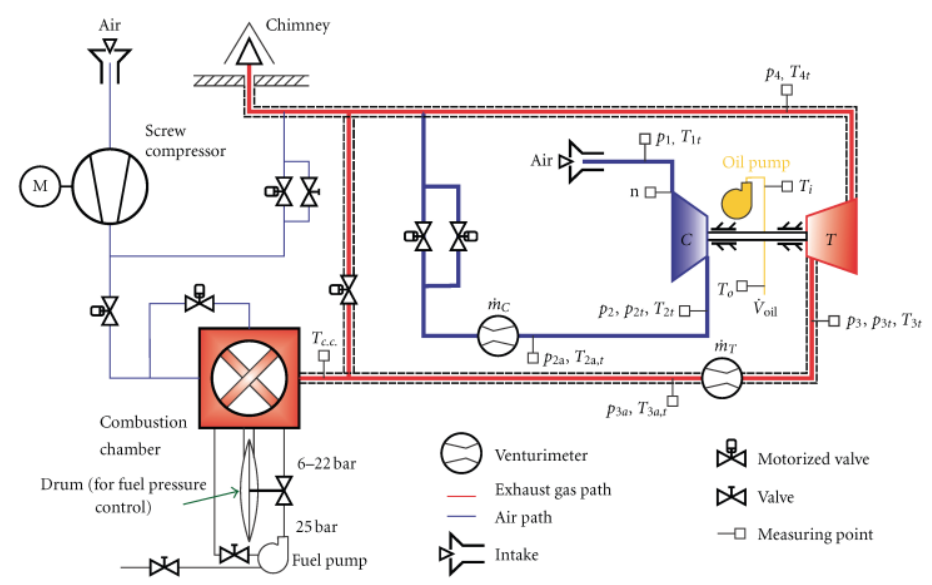

Figure 8: Test stand with measurement devices [5]
Cold measurements consist of feeding the turbine with compressed air slightly above the ambient temperature $\left(50^{\circ} \mathrm{C}\right.$ to $\left.80^{\circ} \mathrm{C}\right)^{3}$. This enables to resemble the adiabatic nature of the turbocharger decoupling the heat transfer from the mechanical losses. The turbine can be tested either in isolation in cold flow test facilities [14] or as part of the whole turbocharger assembly; similar considerations apply to the compressor.

Independent from the type of testing being conducted, the parameters being measured in turbocharger testing are mass flow rate (exhaust gas, air and oil), inlet and exit temperature and pressure to both compressor and turbine, and rotational speed (refer to Figure 8). These parameters are used to generate the performance maps for both the compressor and turbine. Turbine and compressor mass flow rate are generally measured by venturimeters $[5,15]$, hot wires $[8,16,17,18]$ or hot film sensors $[19,20]$, while the oil flow rate is measured by Coriolis flow meters $[11,21,22]$. The temperature is measured using $\mathrm{K}$ type thermocouples $[18,22]$ whereas the oil flow temperature is measured by platinum resistance thermometer $[10,11]$. Pressure is measured by means of piezoelectric or piezo-resistive sensors $[8,10,12,13,16,18,19,20$, and 23]. The rotational speed of the turbocharger is measured by eddy current $[5,23]$ or inductive sensors $[7,13,24]$.

Thermal imaging is a relatively new method to visualize and measure the temperature profile in the turbocharger. This is done by infrared cameras that provide the spatial distribution of temperatures. The resulting profile is used to better model the heat transfer process. Hot measurements and thermal imaging could be successfully used in tandem for modelling approach, as shown by G. Tanda et.al [25].

\subsection{Three-Dimensional Numerical Simulation}

Experimental measurements of heat transfer in turbochargers are usually carried out in order to generate validation data and boundary conditions for simulations. However, detailed measurements of the flow properties and the temperatures in all individual components, interfaces and walls of a turbocharger are time consuming and difficult to obtain due to geometrical complexity and inaccessible locations. So, a complete knowledge of the boundary conditions for computational models is not possible. Hence heat transfer simulation on a complete turbocharger is not currently practiced in the industry.

\footnotetext{
${ }^{3}$ The inlet air temperature to the turbine is determined by the turbine expansion ratio. If not duly accounted for, the pressure drop within the turbine could lead to condensation of the air leaving the turbine thus affecting the quality of the results.
} 


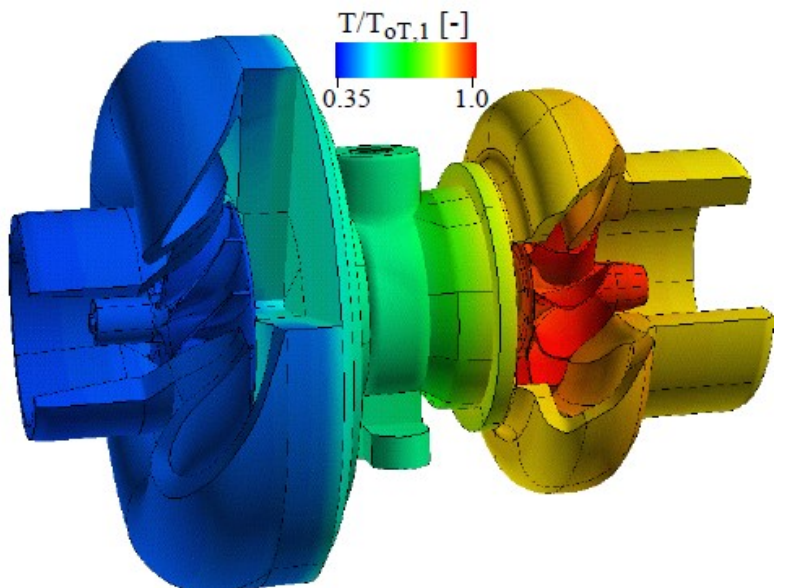

Figure 9: Surface Temperature distribution - CHT simulation [9]

One method to simplify the heat transfer analysis in a 3-D domain, involves solving the solid and fluid domains separately and conjugating the solution to obtain the heat distribution and heat flux in the interface of the domain. This method is known as Conjugate Heat Transfer method (CHT). It requires minimum input, usually derived from experiments and it involves the direct coupling of the fluid flow and the solid body using the same discretization and numerical principle for both the zones [23, 27, 26], with additional options for radiation modelling [28]. The most widely used turbulence model with the CHT method is the shear stress transport model to resolve the thermal boundary layer [29] and free stream region [30]. BaldwinLomax algebraic eddy viscosity turbulence model is also used for its computational efficiency [26, 31]. The computational time of the CHT analysis could be reduced when used in tandem with a 1-D model [32]. The ease and efficiency of the CHT method have made it a standard technique for solving heat transfer problems. Transient temperature calculations are performed in CHT analysis to simulate the heating and cooling process. The temperature distribution obtained from the CHT method is used for the structural analysis using the finite element method (FEM) to determine the thermal stress/strain of turbocharger parts under thermal load [33]. Increasing number of researches on heat transport in turbochargers is studied through CHT [34, 35]. Individual components such as turbine, compressor and bearing housing along with full turbocharger analyses are also done using CHT [35, 36]. This shows the interest of many researchers to increase the level of complexity in 3-D analysis to better model the heat transfer process.

\subsection{One-Dimensional Model}

Another technique to model heat transfer in turbochargers is by using 1-D methods. The advantage of 1-D models is that they are faster, simpler and easier to handle than the 3-D counterpart. One approach to develop 1-D heat transfer models in turbochargers is by considering lump capacitance method.

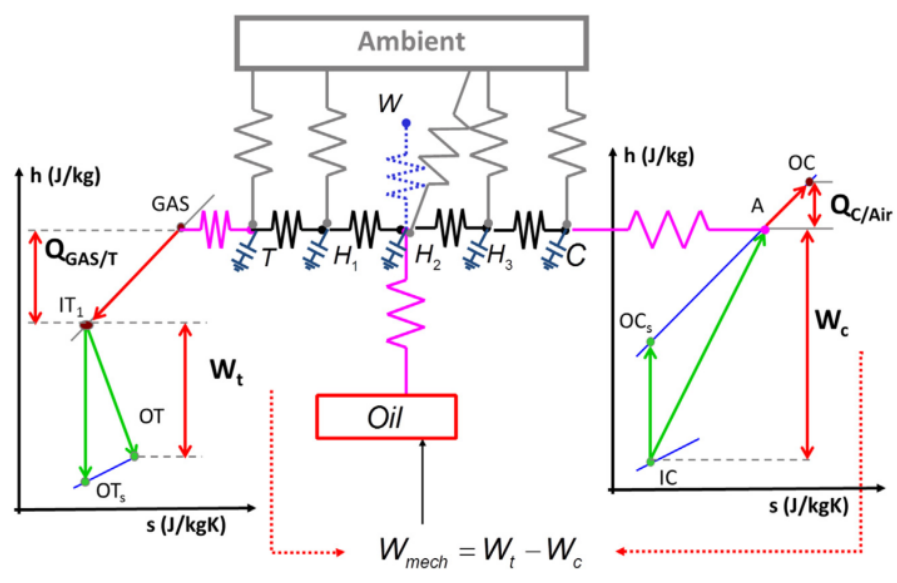

Figure 10: 1-D Lumped model [16]

A lumped capacitance model is a simplified system analogous to an electrical capacitance and resistance model (Figure 10 [16]). It reduces a thermal system into component pieces that are connected by virtual circuits where their interaction property is defined. Air (compressor), gas (turbine), water (bearing housing) and oil (bearing housing) are usually the working fluids of the model. The turbine, compressor and bearing housing are assigned as metal nodes. The energy storage capacity (heat accumulation) of the metal nodes is modeled by the capacitor attached to the nodes. The nodes and their interaction are solved by using the conduction, convection and radiation equations. Experimental measurements are sometimes carried out to calculate the parameters required to solve the conduction, convection and radiation process [30]. The most commonly used relation to solve for conduction is Newton's law of cooling (Eq.8.a), while the convection is solved by SiederTate correlation (Eq.8.b). The radiation relation is not used for insulated turbocharger studies where only internal heat flux is considered. However, Stephan Boltzman's law could be used to define the radiation effects (Eq.8.c).
$\dot{Q}_{\text {conv }}=h A \Delta T$
$\dot{Q}_{\text {cond }}=k A \Delta T / L$
$\dot{Q}_{\text {rad }}=\sigma A T^{4}$

Lump capacitance models in turbochargers assume work and heat transfer to take place independently. The heat transfer process is assumed to take place before and after the expansion/compression while the expansion/compression process itself is usually considered adiabatic. The assumptions made in lumped capacitance models or other 1-D models should be validated in order to have a basis. This validation could be done by conducting focused experiments or 3-D CHT model [34]. Such validation is essential in strengthening the many results found in the literature which are generated by 1-D models. The turbocharger components are usually assumed to be bodies with known geometries (e.g. cylinders, discs and rings). The linear temperature distribution is said to dominate, while its radial distribution is neglected. 
1-D heat transfer models are developed and used in tandem with experimental performance maps to obtain the desired operating point of a turbocharger. Appendix A tabulates all the relevant modeling works by researchers working with turbochargers. The performance maps used in 1-D models may be either hot or cold flow assumption, dependent on the focus of the study. In a method to find the adiabatic efficiency, heat transfer models are used to deduct the heat transfer effect from the given hot maps. Alternatively, a validated heat transfer model can add the thermal effect to a cold map to simulate the diabatic nature of the turbocharger. Most of the past researches focus on increasing the accuracy in predicting the turbocharger outlet properties (i.e. compressor and turbine exit temperature). In current engine models, turbochargers represent a boundary condition for the engine and therefore inaccurate prediction of the outlet temperatures would affect the turbocharger-engine matching.

In the advent of capturing both axial and radial heat transfer, 2D models are developed recently that still computationally cheaper than a full 3-D version and less arduous than experimental works [37]. As research accumulates on the heat transfer modeling, better approaches are inevitable.

\section{REVIEW OF CURRENT RESEARCH}

In the following sections a review of the most relevant work in some specific areas will be discussed.

\subsection{Compressor/turbine flow and performance maps}

Manufacturer maps are usually measured at high temperature $\left(500-600^{\circ} \mathrm{C}\right)$. At this temperature, the heat flux varies in its magnitude and direction for different operating points, the knowledge of which is either intentionally not quantified or disclosed. As the heat transfer effects are not quantified in the manufacturer maps, these maps should be handled carefully when used for simulation. The operating conditions such as the turbine inlet temperature, oil inlet temperature used for turbocharger 1-D models should be the same as those recorded during experiments $[24,38]$, to better model the turbochargerengine matching. Jung et al. [39] were one of the first to perform experimental measurements to determine the impact of heat transfer on performance maps for those operating conditions (low to moderate speeds) which are typically excluded by turbocharger manufacturers. Although they were not successful in fitting the measured performance with any standard polynomial function, their results showed that the difference in the adiabatic and diabatic efficiency is higher in the lower enthalpy drop/low speed conditions and negligible at high speeds [7,38]. Chesse et al. [7] and Cormerais et al. [24] in their experimental evaluation of compressor maps observed that the constant speed lines do not vary when the turbine inlet temperature is increased. They claim that this strengthens the assumption of heat transfer taking place only after the turbine wheel. In a compressor map, the pressure ratio against the corrected mass flow rate remains unchanged thus leading to the conclusion that the aerodynamic behavior of the compressor is not influenced by heat transfer [7, 38, 39], refer to Figure 11.
However, significant changes in the efficiency islands are visible at low speed conditions due to the increased compressor outlet temperature which leads to a significant drop in performance. G.Tanda et al. [25] explained the reduction of heat transfer effects on the diabatic compressor efficiency, at high pressure ratio, to the increasing compressor absorption power.

The performance map generated under diabatic experimental conditions could be converted to an adiabatic performance map by carefully correcting the effect of heat transfer [40]. The vice versa is also true and useful. Thus an enormous literature [41] exists that involves developing correction models that improve the accuracy of performance maps, for compressor [40] and turbine [42].

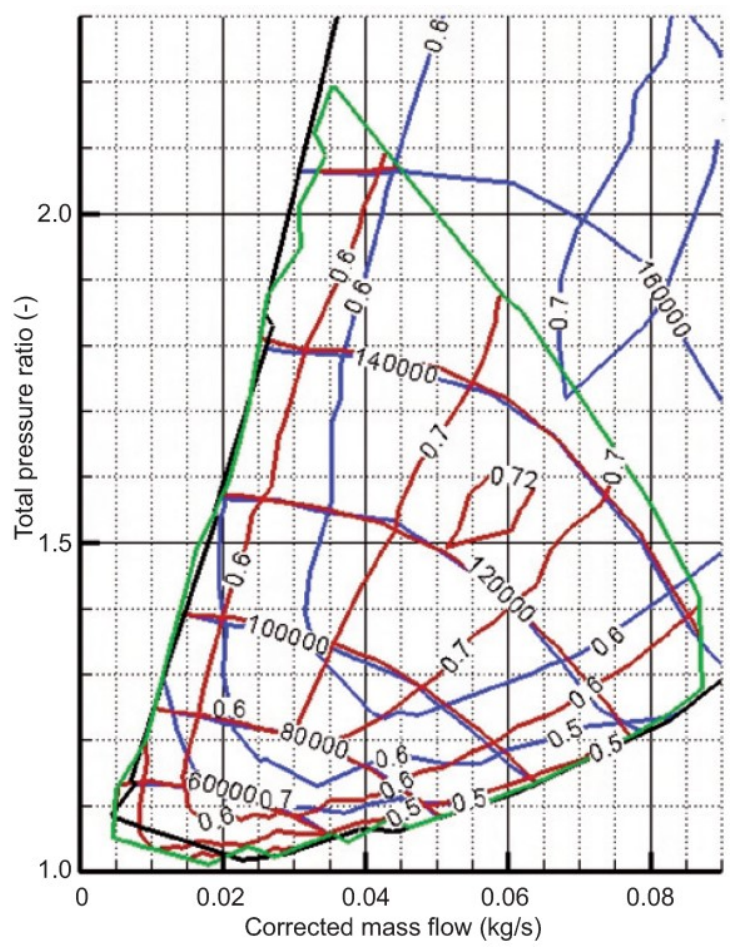

Figure 11: Adiabatic (red) and TIT-turbine $=500^{\circ} \mathrm{C}$ (blue) compressor map [7]

\subsection{Efficiency calculations}

One of the main problems when dealing with the calculation of compressor performance under diabatic conditions is that the shaft power is no equal to the change in enthalpy, so the denominator of Eq. (5) is actually inaccurate. The diabatic efficiency is thus derived by Casey and Fesich [3] by subtracting the heat addition, and relating the heat transfer to the enthalpy rise in an ideal isentropic process, as in Eq. (9),

$\eta_{\text {dia }, C}=\frac{T_{2, i s}-T_{1}}{\left(T_{2}-T_{1}\right)-\frac{q_{12}}{c_{p}}}$

where $q_{12}$ is the specific heat addition between $1 \& 2$ (refer to Fig. 2). Casey and Fesich [3] also argued that using an isentropic process as a reference process to describe diabatic flow is invalid since the entropy does not stay constant for a reversible diabatic flow. Cormerais et al. [24] states that Eq. (5) 
incorporates heat transfer and cannot be called isentropic, and that the isentropic maps cannot be used in the engine model simulation. Sirakov and Fesich [3] tried to capture the heat transfer effect in incremental steps through the compression process using the small stage efficiency, commonly known as the polytropic efficiency, where each step is considered adiabatic with constant heat transfer. The advantage of polytropic efficiency lies in the fact that the integration stage through the process takes place between the real states of the gas at the compressor end, and considers both the dissipation and heat transfer processes. In order to obtain the actual polytropic efficiency in an adiabatic flow, the term diabatic polytropic efficiency (or apparent adiabatic polytropic efficiency) is defined as in Eq. (10)

$\frac{1}{\eta_{p q}}=\frac{1}{\eta_{p}}+\zeta_{q}$

where $\eta_{p}$ is the polytropic adiabatic efficiency and $\zeta_{q}=q_{12} / y_{12}$ is the heat transfer coefficient (ratio between the specific heat addition to useful flow work).

Some manufacturers use the Effective Turbine Efficiency (ETE) (Eq. 11), defined as the ratio of compressor mechanical power to isentropic turbine mechanical power, to define the turbine behavior [6]. This is because the turbine diabatic efficiency given in Eq. (7) exceeds unity especially at low pressure ratios due to relatively higher importance of turbine heat fluxes in comparison to the isentropic enthalpy drops.

$E T E=\frac{\dot{W}_{C}+\dot{Q}_{C}}{\dot{W}_{T s}}$

The effective turbine efficiency of Eq. (11) is used by turbocharger manufacturers because at stabilized conditions the compressor mechanical power can never exceed the turbine mechanical power, thus avoiding conditions in which turbine efficiency exceeds unity. However Serrano et al. [38] observed that at very low pressure ratios the efficiency still can exceed unity.

Olmeda et al. [30] derived a modified turbocharger efficiency taking into account the mechanical losses and heat flux effect given by Eq. (12)

$\eta_{T G}=\eta_{m e c h} \cdot \eta_{T G} \cdot \frac{1+\frac{\dot{Q}_{C}}{\dot{W}_{C}}}{1+\frac{\dot{Q}_{T}}{\dot{W}_{T S}}}$

Sirakov and Casey [10] and Jung et al. [39] showed that the reduction in compressor efficiency is compensated by the increase in turbine efficiency, such that the turbocharger efficiency remains unchanged in presence of heat transfer effects. Sirakov and Casey [10] however argued that there is no major thermodynamic or aerodynamic effect due to heat transfer on turbochargers and that the increased apparent compressor efficiency is an accounting error and not a thermodynamic effect. Jung et al. [39] argued that the experimentally derived maps could be used if the heat transfer effects are accounted for. In order to measure the heat transfer impact, they introduced pseudo efficiency, a combination of parametrized aerodynamic efficiency and measured heat efficiency. By subtracting the aerodynamic efficiency from the measured (pseudo-) efficiency, the heat efficiency was derived.

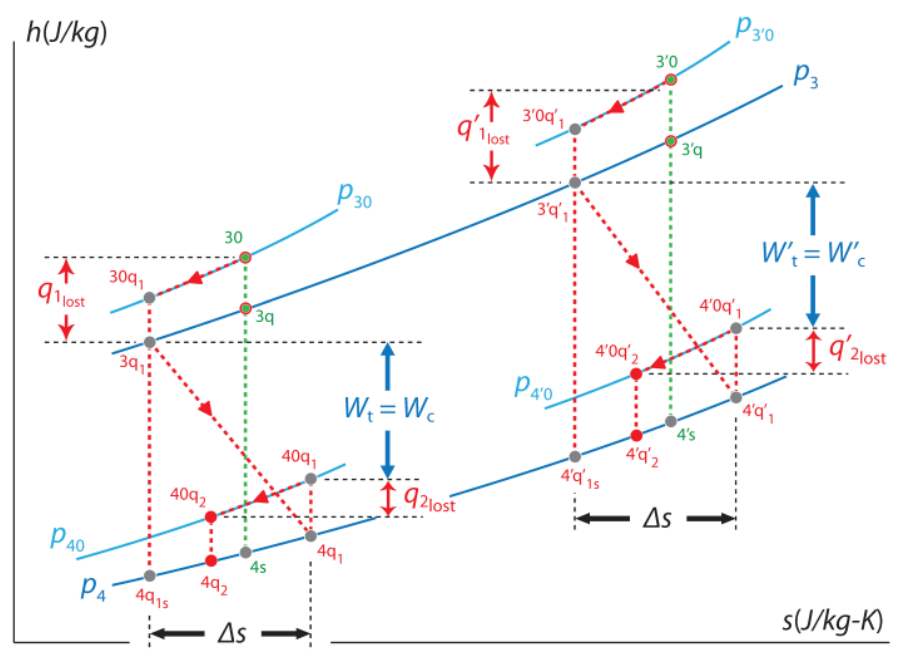

Figure 12: Diabatic expansion with different temperatures at the turbine inlet, but the same expansion ratio and entropy increment [44]

\subsection{Quantification of diabatic/adiabatic efficiency}

The turbocharger is assumed to be adiabatic when the turbine inlet temperature is less than $100^{\circ} \mathrm{C}$ [24]. The exhaust gas temperature and consequently the turbine inlet temperature for typical turbocharger operations are always higher than the condition for adiabatic assumption. Thus heat addition/removal must be accounted to predict the diabatic efficiency. The inclusion of heat transfer in the temperature calculation significantly reduces the error in performance prediction. Chesse et al. [7] showed that the error in predicting the compressor power reaches $48 \%$ when heat transfer is excluded.

Rautenberg et al [1] observed a 3.3 points difference in the adiabatic and diabatic efficiency at 70,000 rpm. The difference between the two efficiency values increases if the distance between the turbine and compressor is reduced [1]. Romagnoli \& Martinez-Botas [17] found that, for a turbocharger installed on-engine, the difference between diabatic and adiabatic efficiency is on average $25 \%$ at low rotational speeds and becomes negligible as the rotational speed increases. In contrast to many findings, Serrano et al. [43] observed in their experimental results that an appreciable deterioration of the compressor efficiency due to positive heat flux to the air mass can only be observed in the low rotational speed range and large inlet turbine temperatures. Otherwise, depending on the turbine inlet temperature, turbocharger speed and mass flow rate, no differences or even improvements in a range between 2 to 4 points of percentage can be observed. The same trend in 
efficiency was also observed on the turbine side for which the efficiency was also found to be higher in hot conditions. This was attributed to the fact that under hot conditions, the oil viscosity is reduced, thus making the turbine efficiency higher due to increased mechanical efficiency. In addition to this, Serrano et al. [43] explained the efficiency rise by highlighting the fact that for the same expansion ratio, the divergence of the constant pressure lines gives a higher enthalpy drop for hot tests than the cold tests (Figure 12). In other words, for a constant entropy increment the enthalpy drop in the turbine is higher in the hot cases than in the cold cases.

Due diligence should be paid during the measurement or modelling of parameters that affect the calculation of component efficiencies. In the computational analysis of turbine, using different near wall treatment is shown to influence the quantification of heat loss that in turn affects the calculation of diabatic efficiency [45]. This is attributed to the importance of accurately modelling the thermal boundary layer upstream of the turbine.

\subsection{Actual work/power}

The compressor power estimated through temperature measured at inlet and outlet does not represent the real work required by the compressor. This is due to the influence of heat exchanged with other turbocharger components that increases or decreases the inlet and exit temperature. The work measured through enthalpy change will have an error equal to the net heat transfer [20], given by Eq. (13),

$\Delta h_{\text {act }}=\Delta h_{\text {work }}+q_{\text {before }}+q_{\text {after }}$

where $q_{\text {before }}$ and $q_{\text {after }}$ is the heat removed/added before/after expansion or compression depending on the process under consideration. Shaaban and Seume [5] showed that a maximum of $35 \%$ error in predicting the actual compressor work is seen if the measured temperature at inlet and outlet of the compressor is used; the error increases with the decrease in rotational speed [5]. Cormerais et al. [24] recommended deducing the heat flux from the measurements in order to obtain the compressor mechanical power. They noted that the direct use of manufacturer maps causes an average of $30 \%$ error in estimating the compressor mechanical power compared to the various 1-D modeling methods, all of which included heat flux [24]. They also observed that the heat transfer can account for $20 \%$ of the compressor mechanical power [24]. Sirakov and Casey [10] derived a relation for the difference between the apparent and real work coefficient under the assumption of constant heat transfer $K_{c}$ and found that it is inversely proportional to product of the cube of the impeller tip speed Mach number and the inlet flow co-efficient.

\subsection{Heat flux in Turbocharger components}

Thermal energy transfer takes place inside the turbocharger throughout its operating condition and the effect of heat transfer cannot be ignored [5, 44]. Serrano et al. [46] provided a lumped capacitance model to accurately model the heat fluxes on turbochargers. The resulting convective coefficients were used to study heat transfer effects on turbine, compressor and the cooling medium. Based on the results from a conjugate heat transfer study on an entire turbocharger, Bohn et al. [31] derived a one dimensional artificial Nusselt number to predict heat transfer for different geometries and operating points, shown in Eq. (14)

$N u_{C}=N u_{0}-\sqrt{p^{2}-\left(\frac{R e_{C}^{2}}{1-\varepsilon^{2}}\right)}$

Burke et al. [20] presented their own convective correlations for turbochargers, and in doing so they made a comparison with Nusselt numbers calculated by other researchers (refer to Table 1). From their analysis it is apparent that different studies have found different solutions when defining the Nusselt number. This is because of the different methods used to define the characteristic length [4, 47, 48, 49]. Burke et. al. [20] plotted the Nusselt number against the Reynolds number (Figure 13), which varies significantly due to changes in the fluid density. Their study also highlighted that care should be taken with Prandtl number variations in modelling, due to the gas composition.

Convection and radiation are the major carriers of heat compared to conduction through bearing housing [2]. The convection and radiation to the surroundings could be properly quantified by accurate measurements of surface temperature [2]. On the compressor side, temperature difference between the inner and outer surface of the housing is noticed to be very small [47]. The thermal energy transferred from the compressor casing to the compressed air, as observed by Olmeda et al. [30], showed to be $10 \%$ of the compressor energy. The bearing housing transports a major portion of the heat (about $2 / 3 \mathrm{rd}$ ) that is received by the compressor and is closely related to the oil temperature [10].

The influence of oil temperature in the heat transported to the compressor is found to be more than the TIT [10]. On the turbine side, Romagnoli and Martinez-Botas [17] found that for increasing turbine inlet temperatures, the difference between the inner and outer wall temperature reaches up to $50 \mathrm{~K}$, which can cause deterioration in the turbine efficiency [50]. 
Table 1: Burke et al. (2015) - Nusselt Numbers [20]

\begin{tabular}{|c|c|c|c|c|c|c|}
\hline \multirow{2}{*}{ Authors } & \multirow{2}{*}{ Source } & \multirow{2}{*}{ Correlation } & \multirow{2}{*}{ Characteristic length } & \multicolumn{3}{|c|}{ Constants } \\
\hline & & & & $\mathbf{a}$ & b & $\mathbf{c}$ \\
\hline Baines et al. (2010) & \multirow{2}{*}{ Gas stand } & \multirow{2}{*}{$N u=a R e^{b} P r^{c}$} & $L_{\text {volute }}$ & 0.032 & 0.7 & 0.43 \\
\hline Cormerais (2007) & & & $D_{\text {inlet }}$ & 0.14 & 0.75 & $1 / 3$ \\
\hline Reyes-Belmonte (2013) & Gas stand & $\begin{array}{l}N u=a \operatorname{Re}^{b} \operatorname{Pr}^{\frac{1}{3}}\left(\frac{\mu_{\text {bulk }}}{\mu_{\text {skin }}}\right)^{0.14} F \\
\text { where } \\
\mathrm{F}=1+0.9756\left(\frac{\frac{D_{\text {inlet }}}{\eta_{\text {max }}}}{\frac{\left(L_{\text {volute }}\right)^{2}}{4 D_{\text {inlet }}}}\right)^{0.76}\end{array}$ & $\frac{\left(L_{\text {volute }}\right)^{2}}{4 D_{\text {inlet }}}$ & $\begin{array}{l}1.07 \\
\\
5.34 \\
0.101\end{array}$ & $\begin{array}{l}0.57 \\
0.48 \\
0.84\end{array}$ & $\begin{array}{l}1 / 3 \\
1 / 3 \\
1 / 3\end{array}$ \\
\hline $\begin{array}{l}\text { Romagnoli and Martinez- } \\
\text { Botas (2012) }\end{array}$ & Theory & $N u=a R e^{b} P r^{c}$ & $\frac{D_{\text {inlet }}}{2}$ & 0.046 & 0.8 & 0.4 \\
\hline
\end{tabular}

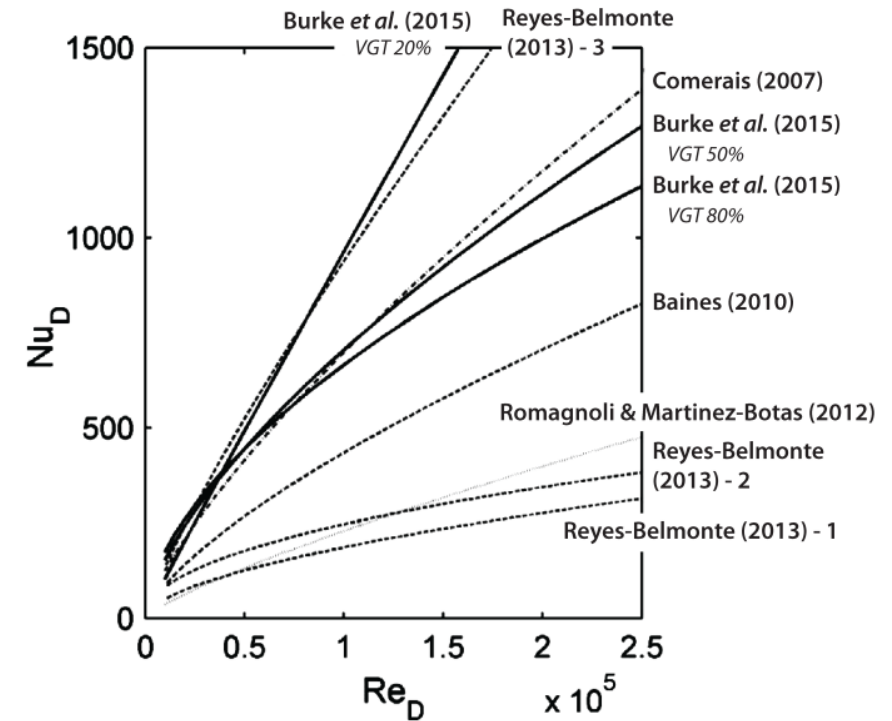

Figure 13: Nu-Re plot - Burke et al. (2015) [20]

For a turbine inlet temperature of 530K, Baines et al. [47] observed that the turbine housing is hotter in the outer surface than the inner side and this trend reverses as the turbine inlet temperature is reduced. Baines et al. [47] concluded that the turbine inlet temperature has much higher influence on the housing temperature than the external heat transfer. Payri et al. [11] observed that the maximum turbine casing temperature varies linearly with the turbine inlet temperature and this is also the case for compressor casing at higher mass flows.

Baines et al. [47] estimated that $50 \%$ of heat losses from the turbine go to ambient. Payri et al. [11] studied in detail the external heat losses and concluded that the major losses comes from the turbine, where the heat transfer reaches a maximum of half the enthalpy drop in the turbine. A higher exposed area and exhaust gas temperature at the turbine inlet leads to higher heat transfer before the expansion process [19].
The importance of heat radiation was investigated by Payri et al. [11] who observed that the compressor casing absorbs more heat radiated from the turbine than it loses through natural convection to ambient; the external heat flux through central housing is negligible. The most important contribution to external heat transfer to the environment will be the turbine, due to its higher temperature (radiative contribution) and big contact area [11]. Estimating the radiation heat flux through studying an exposed turbocharger is recommended to avoid erroneous results. However, many studies focused on the internal heat flux by insulating the turbocharger surface to study the general heat transfer effects neglecting the external heat transfer. Serrano et al. [44] noted that for an externally insulated turbine that allows only internal heat transfer, the heat loss in a turbine reaches a maximum of $70 \%$ of the turbine gas enthalpy at low loads. Serrano et al. [43] calculated the radiated power through the relation $R P=\varepsilon \sigma A\left(T^{4}-T_{a t m}^{4}\right)$ and described the compressor casing as a white body with an emissivity of 0.1 and the turbine casing as a black body with an emissivity of 0.9 as the relation states that the radiated power is proportional to the radiating body temperature. They observed that the power lost by radiation from the turbine is in the order of $10 \%$ to $20 \%$ of the compressor effective power.

\subsection{Parameters affecting Heat Transfer}

The heat transfer that takes place in the turbocharger is affected by many parameters. The turbocharger is operated under the constant influence of fluids such as the working fluid and coolant. These fluids are subjected to hot and cold conditions inside the turbocharger which alters their properties. This section will present analyses of the fluid properties influence on the turbocharger and other factors such as the turbocharger geometry and configuration.

Turbine heat transfer is mainly a function of the turbine inlet temperature whereas the compressor heat transfer also depends on its operating conditions [47]. Fluid properties change during the temperature variation and its effect on the performance calculation could be significant depending on the operating condition [43]. Burke et al. [8] observed that for a range of compressor outlet temperature between $20-200^{\circ} \mathrm{C}$ and transient temperature variation of $26^{\circ} \mathrm{C}$, the changes in $\rho, \mathrm{C}_{\mathrm{p}}$ and $\mu$ are 4- 
$6 \%, 3-5 \%$ and $<0.5 \%$ respectively. However, the effect of fluid property change on heat transfer coefficient is less than $1 \%$ and hence it could be ignored [8]. Serrano et al. [12] studied the influence that variations in specific heat ratio have on the turbine and compressor isentropic temperature. Their research showed that turbocharger flow has to be considered as an ideal gas and not as perfect gas. If this is neglected, the error in the calculation of isentropic temperatures can lead to an overestimation in compressor efficiency of 2.5 points and underestimation in turbine efficiency of 5 points. In addition to this, Serrano et al. [12] also pointed that the presence of ambient humidity should be considered in the compressor and turbine efficiency calculation, only if high efficiency is required. Shaaban and Seume [51] derived a relation to define the deviation of diabatic efficiency from adiabatic efficiency in compressors, given in Eq. (15),

$$
\frac{\eta_{\text {dia }, C}}{\eta_{\text {adi,C }}}=\left(1+K_{C, \text { before }} \xi_{h, C}\right)^{-1} \cdot\left(1+\frac{\xi_{h, C}}{K_{\text {air }}-1} \frac{1}{M_{u 2}^{2}} \frac{1}{\mu\left(1-\frac{\phi_{2}}{\tan \beta_{2, b}}\right)}\right)^{-1}
$$

Shaaban and Seume [51] found that the effect of heat transfer could be reduced with decreasing compressor heat number $\zeta_{h, C}$ (which represents the amount of heat transferred to compressor in non-dimensional form), impeller flow coefficient $\varphi_{2}$, fraction of heat transfer before the compressor impeller $K_{C, \text { before }}$, compressor peripheral Mach number $\mathrm{M}_{\mathrm{u} 2}$, slip factor $\mu$ and blade angle at impeller outlet $\beta_{2, b}$. Their study showed that the compressor heat number and the compressor peripheral Mach number are the parameters which mostly affect the non-adiabatic efficiency. Based on Eq. [15], the deviation of the adiabatic efficiency from the diabatic efficiency is inversely proportional to the compressor peripheral Mach number and compressor heat number.

Romagnoli and Martinez-Botas [17] performed a sensitivity analysis to determine the parameters affecting the heat transfer and the main contributors were found to be those that increase the surface area, such as the diameter of the compressor back plate, bearing housing diameter, turbine diameter and the turbine length. They also noted the importance of radiative heat transfer [17]. Romagnoli and Martinez-Botas [4] performed a regression analysis to determine the contribution of selective parameters to the overall efficiency and found that the contribution of Mach number and temperature are $80 \%$ and $20 \%$ respectively, while the geometry accounted for $2 \%$.

Burke et al. [52] performed a 1-D model simulation to determine the effect of compressor exposed area before compression and found that the increase in the exposed area drives more heat from the bearing housing to the compressor air at intake. Hence a smaller compressor exposed area will reduce the heat transfer, especially at low load/speeds where the difference temperature between the cold compressor and hot turbine is high.

Kumada et al. [53] studied the effect of boundary layer on the heat transfer coefficient, and found that it decreases till the middle of the wall surface above the turbine blade region and increases from thereon to reach a maximum value at the end of rotor blades. They attributed the leakage flow as the cause for the higher value of the heat transfer coefficient at the end of rotor blades.

\subsection{On-engine effects of heat transfer in turbochargers}

In real operating conditions, turbochargers are placed near the engine and this configuration has some effect on the heat exchange that takes place between the turbocharger and its environment. Also, the working of turbocharger is based on the engine operating points and their combined system influences the heat transfer that takes place in the turbocharger. This section will evaluate the effect that the on-engine configuration will have on the heat transfer that takes place in the turbocharger.

Shaaban and Seume [5] observed that at $60,000 \mathrm{rpm}$, for the same operating conditions, the diabatic turbine power is only $55 \%$ of the adiabatic power. The reduction in turbine power and the increase in compressor power may lead to turbo lag. When the engine's operating points are near the compressor surge line, they observed a 3-4\% decrease in the volumetric efficiency due to the heat energy transfer from turbine to compressor. This effect on volumetric efficiency is important in engine starting, no-load and part load operations [5]. Romagnoli and MartinezBotas [17] tested an engine assembly where the turbocharger was placed above the engine and found that the temperature difference between the exhaust gas and the exhaust manifold is higher on the compressor side $(\sim 300 \mathrm{~K})$ compared to the turbine $(\sim 220 \mathrm{~K})$. The difference is due to the relatively cold compressor which can absorb heat from the exhaust manifold more effectively than the turbine [17].

\subsection{Transient Analysis of Heat Transfer}

The exhaust gas of the reciprocating engine has pressure and temperature varying over a small scale of time (in the order of milliseconds). Although the variations are in smaller scale, the heat transfer in the turbocharger is noticed to be affected. Hence a transient analysis is necessary to study the full scope of the heat transfer that takes place inside the turbocharger and the following section will discuss some of the studies performed on this aspect.

Turbocharger maps produced through steady flow experiments contain errors that could not be accounted for by the Heat transfer / Mechanical loss models. These errors could only be reduced by generating the maps under real pulsating and transient flow conditions. Relatively early studies, such as that by Cormerais et al. [54] had identified the need for experimental data in order to model for transient heat transfer behavior. In transient conditions, the properties of the fluid and metal in the turbocharger take time to stabilize. For instance, a rapid increase in turbine power, will lead to an increased air temperature after the compression. However, the temperature of the compressor casing will not experience the same variation since heat transfer develops slower than the gas temperature [8]. For testing purposes, Burke et al. [8] recommends small changes in the 
operating points in order to reduce the thermal stabilization time. Burke et al. [20] illustrated the importance of transient analysis by observing variation in heat transfer characteristics between the gas, wall and ambient in a relatively short time span. They showed that heat flow from the gas to the housing wall peaks at the beginning of transient operation and falls to half the initial value within three minutes. They also found that for a step reduction of TIT by $100^{\circ} \mathrm{C}$, the maximum heat flow is reversed in the turbine housing, where the heat flows from the wall to gas [47]. Burke et al. [20] observed that even in transient conditions, the exhaust gases are always hotter than ambient and noted a constant ratio of heat transfer from the turbine housing to the surroundings, as there are only minor changes in the turbine housing temperature with constant ambient temperature. Burke [19] similarly found that the change in TIT produces a proportional deviation between the initial heat transfer and the settled value. Burke et al. [20] carried out tests on a 2.2 liter diesel engine and it was found that in $100 \mathrm{~s}$, the heat flow fell from an initial value of $6.6 \mathrm{~kW}$ to $0.6 \mathrm{~kW}$ for a TIT change from $300^{\circ} \mathrm{C}$ to $480^{\circ} \mathrm{C}$. However, the flow pulsation has little effect on the heat transfer as the thermal inertia of the turbine housing shows a larger time scale than the exhaust pulsation [20].

Aghaali and Angstrom [55] investigated heat transfer in transient operations alongside simulation with commercially available software - illustrating the importance of loading history and the effect of software model multipliers. Aghaali and Angstrom [55] concluded that heat transfer effects could not be accurately included in the multipliers used for turbines and compressors in commercial engine simulation software. In this case a heat sink and heat source were used upstream of the rotor and downstream of the compressor respectively, in order to include heat transfer effects in the model. Earlier studies had set out to predict transient heat transfer, and the subsequent engine performance, by using 1-D gas dynamics codes. The study by Gallindo et al. [56] was the first to calculate wall temperatures, with thermal inertia taken into account, by using a 3-node finite difference scheme. The model was used to predict transient operation of a HSDI turbocharged engine.

A further study by Aghaali and Angstrom [57] focused primarily on the wall temperatures of the turbocharger housing, and the impact upon transient performance. It was observed that wall temperatures in transient operation are predictable (with maximum difference of $1 \%$ ) from the values of compressor inlet temperature, turbine inlet temperature, water inlet temperature, oil inlet temperature, compressor pressure ratio and the velocity profile of the flow.

\subsection{Influence of Individual Components on Heat Transfer}

Heat is carried differently based on the thermal property of the material and geometry of the structure. Turbocharger consists of several components that have different material and geometry and this influences the heat transfer that takes place. Moreover, the location of each component also affects the way the heat is transported within the turbocharger. Hence this section will scrutinize the influence of individual components on the overall thermal energy transfer of the turbocharger.
In the turbine blades, thermal conductivity of the blade material allows for an even distribution of heat on the pressure and suction side. Heuer et al. [58] showed that the difference in temperature between the pressure side and suction side of the blade is $3 \mathrm{~K}$ at the hub and $1 \mathrm{~K}$ at the tip. In transient analysis, the turbine impeller blades show different heating rate depending on the wheel location [58]. This observation was supported by Rehman [28] in his transient analysis of the turbine blade, where he observed that during the heating cycle, the maximum temperature is at the turbine blade inlet and the minimum at the wheel back disk, whilst the reverse happens during the cooling cycle. Diefenthal et al. [59] identified the higher temperature gradients at the back of the turbine wheel near the axial gap and back of the blade near the leading edge. In a detailed investigation on the heat transfer contribution of individual components to the compressor, $\mathrm{Gu}$ et al. [60] found that the external heat transfer through the shaft and casing top surfaces reduce the total pressure ratio of the compressor. The shaft is considered to be the most sensitive part concerning the external heat transfer. The increase in impeller shaft temperature will cause a proportional increase in the fluid temperature absorbed through the hub. An absence of internal heat transfer accounts for nearly $1 \%$ change in the diabatic efficiency of the compressor [60]. $\mathrm{Gu}$ et al. [60] concluded that the heat loss through the internal convection could be reduced by preventing the heat flow through the shroud and recommends shielding or cooling of the shroud surface, while the hub contribution to the internal heat transfer is lower.

\subsection{Structural Effects due to Heat Transfer}

Thermal energy carried by the hot exhaust gas has detrimental effect on the turbocharger structures (refer to Figure 14 [32]). This influence could be seen over a period of cycles after which the structure starts to show damage. This section will further discuss the effect of heat on the structures.

A complete structural analysis of a turbocharger is carried out considering three types of load - Centrifugal load, Aerodynamic load and Thermal load. Our point of interest lies in the contribution of the thermal load on the turbocharger components. In analyzing the impeller stress for high pressure ratio turbocharger compressor, Zheng et al. [33] concluded that the contribution of centrifugal, aerodynamic and thermal load to the compressor impeller is $98 \%, 0.25 \%$ and $2 \%$ respectively. The thermal load contribution stayed constant at $2 \%$ throughout the operating conditions for different pressure ratio. However, the universal tensile strength of the material decreased at higher temperature, thus reducing the maximum pressure ratio from 4.6 to 4.2 [33]. 


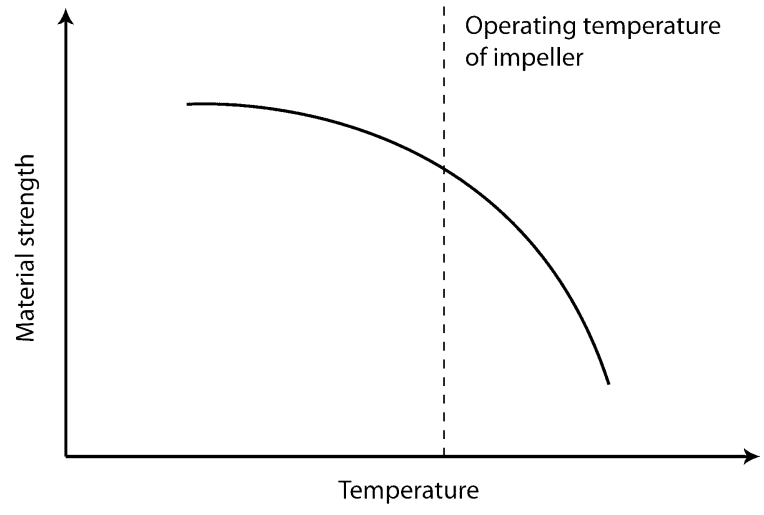

Figure 14: Material strength vs. Temperature [32]

Ahdad et al. [61] performed a fatigue analysis on turbine housing under transient conditions and observed tensile and compressive stress in the cooling and heating phase respectively. The accuracy of the structural analysis is improved in the transient analysis as the observation of stress during the cooling and heating process is vital. In the turbine housing, the tongue and divider wall are subjected to the maximum thermal stress $[61,29]$. Ahdad et al. [61] noticed a crack in the divider wall after 300 cycles (50 hours). Heuer et al. [29] analyzed the turbine housing with knobs acting as cooling fins, and observed that it helped to distort the thermal distribution in divider walls. Heuer et al. [58] performed a thermal stress analysis and found that the maximum stress in the turbine rotor occurs at the blade root fillet radii and the undercut (back) and recommends the improvement of back wall design.

\subsection{Coolants and Cooling Effects in Turbochargers}

Coolants are the most widely employed method to mitigate internal heat transfer due to its effectiveness in transporting the heat away from the turbocharger. This section will evaluate the effect of coolants and other methods in reducing the detrimental effect of thermal energy transfer.

The cooling liquid (such as water) or oil has significant contribution in reducing the effect of heat transfer. Serrano et al. [38] tested two turbochargers (one with water cooling and another with no cooling circuit) in adiabatic and hot conditions (600K turbine inlet). Their results showed that both the water cooled and non-water cooled turbochargers show a similar difference in the compressor efficiency between the diabatic and adiabatic test conditions. This means that water cooling is not an effective solution at low rotational speeds and the reason for that was attributed to the high residence time of gas and air. However at mid-high speed (greater than $110 \mathrm{krpm}$ ) the water cooled turbocharger shows less difference between the compressor diabatic and adiabatic efficiency. This means that the coolant is effective in removing heat away from the compressor side. On the other hand, for non-cooled turbochargers, the difference between the diabatic and adiabatic efficiency is more significant [38]. Serrano et al. [44] also observed that for a non-cooled turbocharger, heat fluxes to the oil are more important than for a cooled turbocharger. This is because, in a cooled turbocharger, cooling water acts as a heat sink and reduces the heat flux to the oil. In addition to this, the importance of the cooling liquid is observed at low load conditions where the heat removed by cooling can reach up to $60 \%$ of the turbine gas power drop.

The bearing housing that contains the oil and rotating components is vital to the thermal management of a turbocharger. The bearing system is carefully designed to accommodate the thermal flow between the turbine and compressor. Andres et al. [36] developed a thermohydrodynamic computational model of the turbocharger bearing system (floating-ring) that carefully documents the pressure and thermal profile of each component including the lubricant. Shaaban and Seume [5] showed that the heat energy transfer to the oil is $30 \%$ of the total heat transfer from the turbine. They insulated the turbine casing to observe the effect of heat shield and it proved to reduce the heat transfer to the bearing housing. They further stated that the turbo lag can be reduced with an insulated turbine that could be made in a comparatively smaller size resulting in smaller rotor inertia than the non-insulated turbine. Serrano et al. [44] noted that when the oil temperature is higher than the compressed air, the compressor outlet temperature is increased. However at high pressure ratio, the compressed air is heated higher than the oil such that the heat flow is now reversed. Adjusting the oil temperature with respect to the heat flux magnitude and direction will reduce any detrimental effect caused by the heat transfer from the turbine to compressor. Baines et al. [47] showed that in diabatic conditions the bearing housing surface temperature follows closely the oil exit temperature, where the bearing temperature is partway between the oil inlet and exit temperatures. The difference between the oil inlet and exit temperatures can be as high as $60 \mathrm{~K}$ in diabatic conditions for high compressor flow rate. As for adiabatic testing, this difference is only about 10K [47]. Romagnoli and Martinez-Botas [17] observed that for an increasing temperature, the oil viscosity decreases with a consequent increase in Reynolds number. They stated that the reduced viscosity allows more heat to be absorbed by the oil, thereby increasing its cooling effect [17].

The aerodynamic effects in the blades themselves contribute to some cooling effect. Hellström et al. [62] observed in their 3-D simulation with diabatic walls that the vortex structures inside the turbine blades mixes the cooled down fluid from the thermal boundary layer (formed on the surface walls) with the hot gas in the core providing a cooling effect. Lei [32] tried to reduce the temperature of the compressor impeller by cooling down the sealing plate (Figure 15). In this way the heat transferred to the impeller is driven to the base of the impeller; the results showed that a temperature reduction of $3 \%$ could be achieved. However, the cooling work necessary will reduce the overall system efficiency. They nevertheless reduced the impeller temperature by $3 \%$ using a thermal insulation at the impeller base and outer periphery [32].

Care must be taken in the cooling system design by using the accurate cooling liquid temperature that takes into effect various heat transfer processes [46]. 


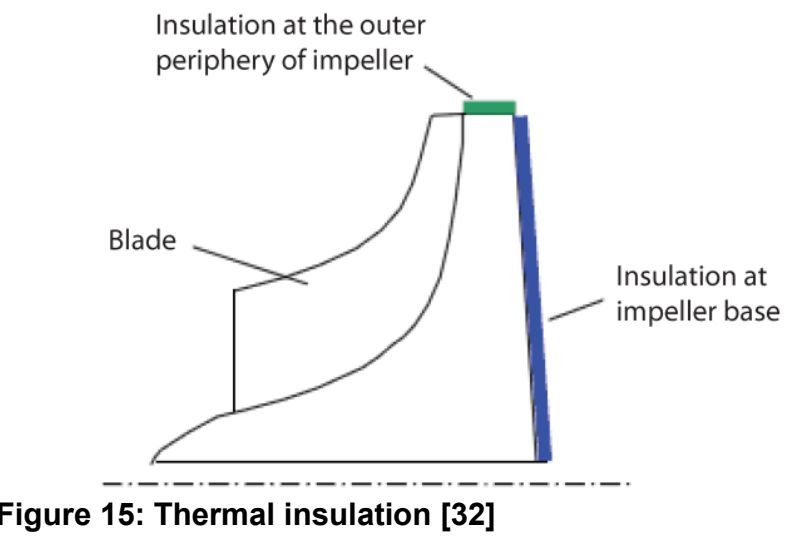

\section{STATE OF THE ART TECHNOLOGY}

The study of heat transfer phenomena has informed the design and component layout of turbochargers, and its influence can be observed in state of the art designs and suggested modifications by researchers. Oil has long been used in the bearing housing to absorb the frictional losses in the bearings. Surprisingly, the oil serves as an additional heat sink for the heat transfer taking place at diabatic conditions. Oil is proved to absorb nearly $30 \%$ of the thermal energy transfer taking place between the turbocharger components [5]. Liquid cooling circuits are used for the sole purpose of absorbing heat from the bearing housing where the heat flows from the turbine to compressor at low to mid speed operating points and sometimes, reversal of heat flow at higher speeds. They can be used as an effective cooling medium in conjunction with oil.

The exhaust pipes are a major source of radiative and convective heat transfer to the turbocharger. A heat shield could be installed below the pipes to protect turbochargers from accumulating heat in their housings [63] (Figure 16). Other potential places where heat shields could be applied are the impeller back surface and the side of the turbine housing facing the compressor. Placement of knobs on the turbine divider walls are shown to act as cooling fins [62]. Structures placed on the housings that generate vortex flows may reduce the heat at temperature concentrated areas. Arrangement of turbine and compressor in a turbocharger affects the thermal energy transport. Placement of the compressor close to the turbine will reduce the effect of coolants and allows quicker transport of heat. A standard distance between the turbine and compressor parts is necessary for better thermal management without compromising the compactness of the product.

Another configuration that is susceptible to increased thermal energy loss is the engine-turbocharger arrangement. Placement of turbocharger away from the engine will reduce significant work loss. Some of the components inside the turbochargers are identified to be the main conductors of heat. Such surfaces could be identified and locally insulated with low conductivity materials to prevent the heat flow to sensitive parts. Material selection is also a vital preventive measure in designing a turbocharger. It is recommended that Impeller blades and component housings are to be made of high conductivity materials that can evenly distribute the heat and avoid hot spots.

\section{TRENDS AND SUGGESTIONS FOR FUTURE RESEARCH}

Research on heat transfer in turbochargers is far from being fully exhausted. Prominent research groups worldwide are looking into heat transfer in turbochargers which explains for the urgency to find a common methodology to address and include heat transfer in the turbocharger-engine matching exercise, thus improving the performance of exhaust gas energy recovery and durability of the turbocharger.

It is worth noting that heat transfer in turbochargers is unavoidable, even though there are efforts on many fronts leading to improvements. These improvements on materials, cooling techniques and turbochargers configuration will contribute towards mitigating some of the detrimental effects of heat transfer on turbochargers performance. Nevertheless, the current trends on engine downsizing, boosting requirements (higher compression ratio leading to higher exhaust gas temperatures) and compact powertrain units (for instance integrated exhaust manifold), limit the chances to achieve a complete insulation. With this in mind, there are still several areas which can be investigated:

- Simulation and modelling - current methods to predict the amount of heat transfer to the compressor rely on curve fitting to experimental data. This might be unavoidable due to the myriad of different turbocharger geometrical configurations. However commercial 1-D software still does not have a common add-on/technique to account for heat transfer in turbochargers,

- Assessment of heat transfer impact during start-up of the engine - some preliminary researches have shown that the heat loss through the turbine housing plays a significant role on turbo-lag and reducing engine volumetric efficiency [5],

- Heat transfer under pulsating flow conditions - limited analysis has being done to understand the dynamics of heat transfer due to the pulsating nature of the exhaust gas. This is due to two main factors:

- Difficulty to conduct pulsating flow measurements in hot conditions - at the present a simple experimental methodology has yet to be proposed due to the harsh environment in which flow sensors would be operating.

- Computational constraints - CFD simulations under pulsating flow are intensive in terms of hardware and time requirement.

- Experimental data - besides the measurement of hot exhaust gas under pulsating flow, the quality of experimental data limits the development of accurate heat transfer models. For instance, bearings are believed to play an important role in the heat generation. However it is difficult to directly measure bearings temperature during real operating conditions. 

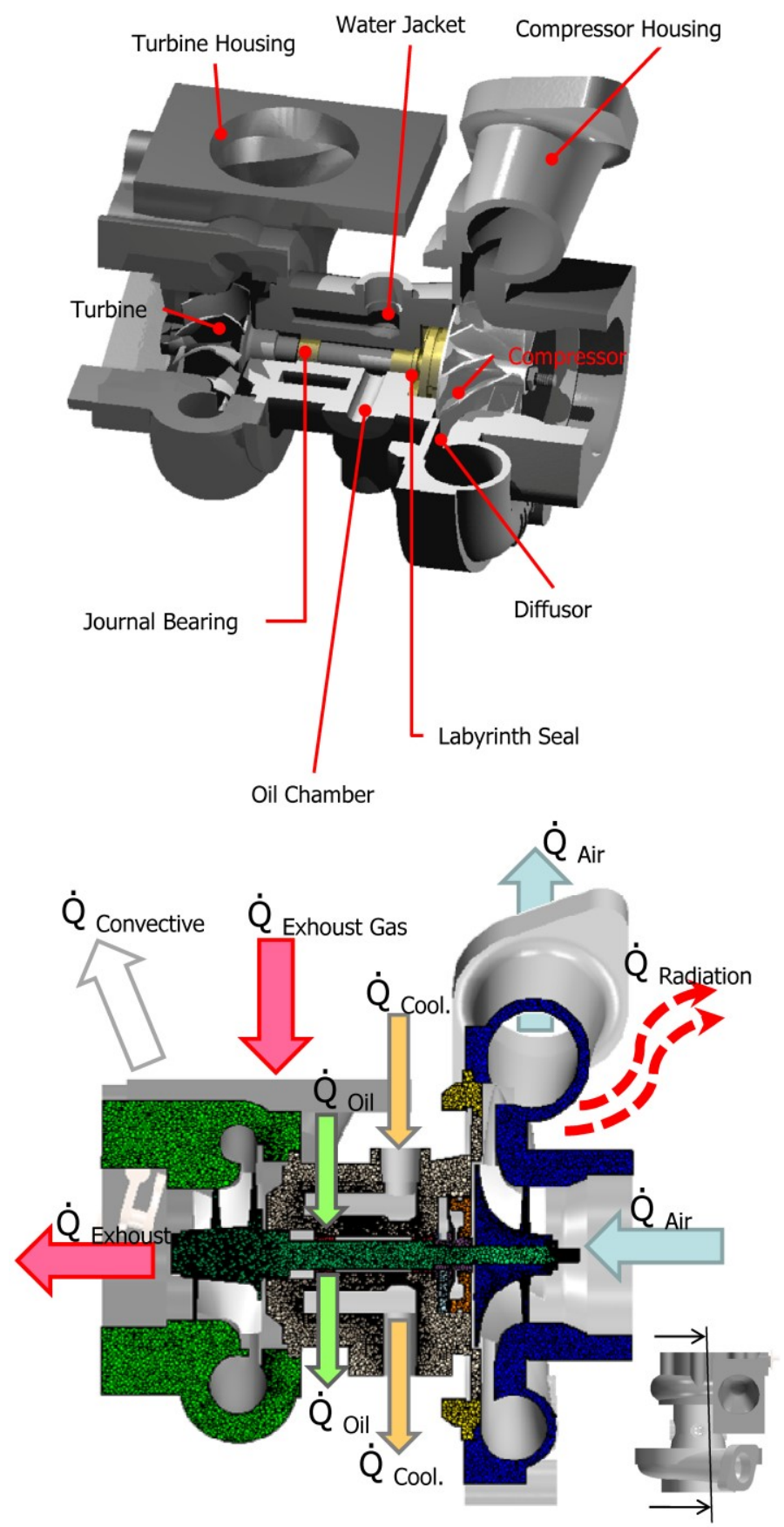

Figure 16: Coolant effect [63]

Finally there is another research area which is envisaged to gain increasing interest in the future. The current trend on powertrain electrification (mild-hybridization) has brought back to life the concept of Electrically Assisted Turbocharging. This consists of an electric machine directly coupled to the shaft of the main turbocharger, which can be used either as an electric generator (recovering energy from the exhausts) or an electric motor (adding energy to the turbocharger shaft during transient operation) $[64,65,66]$. If the electric motor is positioned between the turbocharger compressor and the turbine, it will require a cooling strategy which will inevitably affect the heat transfer within the turbocharger.

\section{CONCLUSIONS}

The current paper discusses the main research activities focusing on heat transfer in turbochargers. As per the stated aim of this review, this paper has provided the most complete review of turbomachinery heat transfer to date. The article begins by explaining the problem statement where heat transfer in turbochargers is not considered in experiments as well as in engine simulation, leading to erroneous results during the engine-turbocharger matching. The article then elaborates on the three main research domains: experimental, 3-dimensional and 1-dimensional modeling, outlining the current state-of-the-art in each of the domain. The article also reviews the results obtained by researchers by looking into many aspects of heat transfer within a turbocharger, its implication on the engine system as well as environment, transient effects, internal components and their influence and cooling characteristics. Findings of many researchers, past and present, as well the authors' own analyses have in fact corroborated to a conclusion that heat transfer could not be neglected in turbocharger-engine matching, thus highlighting the need to accurate experimental results and validated simulation. Finally some recommendations and outlook on future research activities on heat transfer in turbochargers was also provided.

\section{ACKNOWLEDGMENT}

The authors would like to thank funding bodies from Singapore, United Kingdom and Malaysia. This work is partly funded by Universiti Teknologi Malaysia Research Grant VOT 4L174. 


\section{NOMENCLATURE}

\section{English Description}

a

$\mathrm{A}_{\text {conv }} \quad$ Area over which convection occurs

$\mathrm{A}_{\text {turb,surf }}$

b Constant

C Thermal capacitance

c Constant

$\mathrm{C}_{\mathrm{p}} \quad$ Specific heat at constant pressure

D Diameter

F View factor

Gr Grashof number

h Heat transfer coefficient / Specific

Enthalpy

h.A Convective conductance

$\bar{h} \quad$ Convective heat transfer coefficient

$\mathrm{k}$ Thermal conductivity of the fluid

K Thermal conductance

$\mathrm{K}_{\text {cond,b }} \quad$ Lumped conduction parameter to

cond,b bearing

$\mathrm{K}_{\text {cond, } \mathrm{m}}$ Lumped conduction parameter to

manifold

L Length

$\mathrm{M} / \mathrm{m} \quad$ Mass

$\mathrm{N} \quad$ Speed

$\mathrm{Nu} \quad$ Nusselt number

p Pressure

P Power

Pr Prandtl number

Q Heat

q Specific heat transfer

$\dot{Q} \quad$ Heat power / heat flux

R Gas constant

Ra Rayleigh number

Re Reynolds number

S Entropy

T Temperature

W Work

$\mathrm{X} \quad$ Distance

$\mathrm{Y}$ Mass fraction

\section{Greek Description}

Unit

\begin{tabular}{|c|c|c|c|}
\hline Unit & $\alpha$ & $\begin{array}{l}\text { Heat transfer area distribution } \\
\text { coefficient }\end{array}$ & UIIt \\
\hline $\mathrm{m}^{2}$ & $\alpha$ & Turbine capacitance fitting constant & - \\
\hline & $\gamma$ & Ration of specific heats & - \\
\hline & $\varepsilon$ & Emissivity & - \\
\hline & $\eta$ & Efficiency & - \\
\hline & $\kappa$ & Thermal conductivity & $\mathrm{W} / \mathrm{m} . \mathrm{K}$ \\
\hline & $\lambda$ & Work input or enthalpy rise coefficient & - \\
\hline J/kg.K & $\mu$ & Dynamic viscocity & Pa.s \\
\hline $\mathrm{m}$ & $\mu_{\text {bulk }}$ & $\begin{array}{l}\text { Dynamic viscocity at bulk fluid } \\
\text { temperature }\end{array}$ & $\mathrm{Ns} / \mathrm{m}^{2}$ \\
\hline - & $\mu_{\text {skin }}$ & $\begin{array}{l}\text { Dynamic viscocity at fluid skin } \\
\text { temperature }\end{array}$ & $\mathrm{Ns} / \mathrm{m}^{2}$ \\
\hline $\mathrm{J} / \mathrm{kg}$ & $\sigma$ & Stefan Boltzmann's constant & $\mathrm{W} / \mathrm{m}^{2} \mathrm{~K}^{4}$ \\
\hline
\end{tabular}

$\mathrm{W} / \mathrm{K}$

$\mathrm{W} / \mathrm{m} . \mathrm{K}$

$\mathrm{W} / \mathrm{K}$

Abbreviation

CHT

COT

ETE

HTM

$\mathrm{m}$

$\mathrm{kg}$

rpm

-

$\mathrm{Pa}$

$\mathrm{W}$

-

-

W

$\mathrm{J} / \mathrm{kg}$

W

TIT

J/mol.K TOT

- UDC

- $\quad$ UTS

$\mathrm{J} / \mathrm{K} \quad \mathrm{VGT}$

$\mathrm{K}$

$\mathrm{J}$

$\mathrm{m}$

\section{Description}

Conjugate heat transfer

Compressor outlet temperature

Effective Turbine efficiency

Heat transfer model

Large eddy simulation

Look up model

New European drive cycle

Original equipment manufacturer

Pressure ratio

Research and development

Radiation power

Shear stress transport

Turbine diabatic efficiency

Turbine inlet temperature

Turbine outlet temperature

Urban drive cycle

Universal tensile strength

Variable geometry turbine 


\section{Subscript Description}

0

1 Gas state before compression

2 Gas state after compression

3 Before expansion in turbine

4 After expansion in turbine

12 Process between 1-2 (before to after compressor)

a

act

adi

air

$\mathrm{amb}$

$\mathrm{b}$

$\mathrm{b} / \mathrm{B}$

$\mathrm{BH}$

BP

$\mathrm{C}$

cond

conv

dia

env

ext

$\mathrm{H}$

$\mathrm{i}, \mathrm{j}$

int

is

1

$\mathrm{m}$

mech

oil

$\mathrm{p}$

q

$\mathrm{rad}$

$\mathrm{s}$

$\mathrm{S}$

$\mathrm{t}$

$\mathrm{T}$

TG
After compression / Apparent

Actual

adiabatic

Air

Ambient

Before compression

Bearing housing

Bearing housing

Back plate

Compressor / Compressor metal nodes

Conduction

Convection

diabatic

Enviroment

Exterior

Housing / Housing metal nodes

Consecutive metal nodes

Interior

Isentropic

Working fluid

Manifold

Mechanical

Oil

Diabatic / specific heat transfer

Radiation

Surface

Shaft

Total / Turbine

Turbine / Turbine metal nodes

Turbocharger polytropic

\section{References}

1. Rautenberg, M., \& Kammer, N. (1984, October). 'On the Thermodynamics of Non-Adiabatic Compression and Expansion Process in Turbomachines. InICMPE, Proceedings of the 5th International Conference for Mechanical Power Engineering, Cairo, Egypt.

2. Westin, F., Rosenqvist, J., \& Ångström, H. E. (2004). Heat Losses from the Turbine of a Turbocharged SIEngine-Measurements and Simulation (No. 2004-010996). SAE Technical Paper.

3. Casey, M. V., \& Fesich, T. M. (2010). The efficiency of turbocharger compressors with diabatic flows. Journal of engineering for gas turbines and power, 132(7), 072302.

4. Romagnoli, A., \& Martinez-Botas, R. (2012). Heat transfer analysis in a turbocharger turbine: An experimental and computational evaluation. Applied Thermal Engineering, 38, 58-77.

5. Shaaban, S., \& Seume, J., "Impact of Turbocharger Non-Adiabatic Operation on Engine Volumetric Efficiency and Turbo Lag," International Journal of Rotating Machinery, vol. 2012, Article ID 625453, 11 pages, 2012. doi:10.1155/2012/625453

6. Malobabic, M. \& Rautenberg, M., (1987), Adiabatic and non-adiabatic efficiencies of small turbochargers, in GTSJ International Gas Turbine Congress, Tokyo, Japan, 1987. Paper IGTC-105, pp. I57-I64.

7. Chesse, P., Chalet, D., \& Tauzia, X. (2011). Impact of the heat transfer on the performance calculations of automotive turbocharger compressor. Oil \& Gas Science and Technology-Revue d'IFP Energies nouvelles, 66(5), 791-800.

8. Burke, R., Olmeda, P., \& Serrano, J. R. (2014, October). Dynamic Identification of Thermodynamic Parameters for Turbocharger Compressor Models. In ASME 2014 Internal Combustion Engine Division Fall Technical Conference (pp. V002T06A006V002T06A006). American Society of Mechanical Engineers.

9. Bohn, D., Moritz, N., \& Wolff, M. (2003, January). Conjugate flow and heat transfer investigation of a turbo charger: Part ii-experimental results. In ASME Turbo Expo 2003, collocated with the 2003 International Joint Power Generation Conference (pp. 723-729). American Society of Mechanical Engineers.

10. Sirakov, B., \& Casey, M. (2013). Evaluation of heat transfer effects on turbocharger performance. Journal of Turbomachinery, 135(2), 021011.

11. Payri, F., Olmeda, P., Arnau, F. J., Dombrovsky, A., \& Smith, L. (2014). External heat losses in small turbochargers: Model and experiments. Energy,71, 534-546.

12. Serrano, J. R., Dolz, V., Tiseira, A., \& Páez, A. (2009). Influence of environmental conditions and thermodynamic considerations in the calculation of turbochargers efficiency (No. 2009-01-1468). SAE Technical Paper. 
13. Cormerais, M., Hetet, J. F., Chesse, P., \& Maiboom, A. (2006, January). Heat transfers characterisations in a turbocharger: Experiments and correlations. InASME 2006 Internal Combustion Engine Division Spring Technical Conference (pp. 53-64). American Society of Mechanical Engineers.

14. Szymko, S., McGlashan, N. R., Martinez-Botas, R., \& Pullen, K. R. (2007). The development of a dynamometer for torque measurement of automotive turbocharger turbines. Proceedings of the Institution of Mechanical Engineers, Part D: Journal of Automobile Engineering, 221(2), 225-239.

15. Rautenberg, M., Mobarak, A., \& Molababic, M. (1983). Influence of heat transfer between turbine and compressor on the performance of small turbochargers JSME Paper 83-Tokyo-IGTC-73. In International Gas Turbine Congress.

16. Serrano, J. R., Olmeda, P., Arnau, F. J., Dombrovsky, A., \& Smith, L. (2015). Turbocharger heat transfer and mechanical losses influence in predicting engines performance by using one-dimensional simulation codes. Energy.

17. Romagnoli, A., \& Martinez-Botas, R. (2009, January). Heat transfer on a turbocharger under constant load points. In ASME Turbo Expo 2009: Power for Land, Sea, and Air (pp. 163-174). American Society of Mechanical Engineers.

18. Serrano, J.R., Arnau, F.J., Dolz, V., Tiseira, A., \& Cervello, C., (2008, August), A model of turbocharger radial turbines appropriate to be used in zero- and onedimensional gas dynamics codes for internal combustion engines modelling, In Journal of Energy Conversion and Management, Vol. 49, Issue 12 (pp 3729-3745), doi: 10.1016/j.enconman.2008.06.031.

19. Burke, R. D. (2014). Analysis and Modeling of the Transient Thermal Behavior of Automotive Turbochargers. Journal of Engineering for Gas Turbines and Power, 136(10), 101511.

20. Burke, R. D., Vagg, C. R. M., Chalet, D., \& Chesse, P. (2015). Heat transfer in turbocharger turbines under steady, pulsating and transient conditions. International Journal of Heat and Fluid Flow, 52, 185-197.

21. Verstraete, D., \& Bowkett, C. (2015). Impact of heat transfer on the performance of micro gas turbines. Applied Energy, 138, 445-449.

22. Serrano, J.R., Olmeda, P., Paez, A., \& Vidal, F., (2010, February), An experimental procedure to determine heat transfer properties of turbochargers, In the Journal of Measurement Science and Technology, Vol. 21, Issue 3, doi: 10.1088/0957-0233/21/3/035109.

23. Burke, R. D., Olmeda, P., Arnau, F. J., \& ReyesBelmonte, M. (2014, October). Modelling of turbocharger heat transfer under stationary and transient engine operating conditions. In 11th International Conference on Turbochargers and Turbocharging: 13-14 May 2014: 13-14 May 2014 (p. 103). Elsevier.
24. Cormerais, M., Hetet, J. F., Chesse, P., \& Maiboom, A. (2006). Heat transfer analysis in a turbocharger compressor: Modeling and experiments (No. 2006-010023). SAE Technical Paper.

25. Tanda, G., Marelli, S., Marmorato, G., \& Capobianco, M. (2017). An experimental investigation of internal heat transfer in an automotive turbocharger compressor. Applied Energy, 193, 531-539.

26. Heuer, T., \& Engels, B. (2007, January). Numerical analysis of the heat transfer in radial turbine wheels of turbo chargers. In ASME Turbo Expo 2007: Power for Land, Sea, and Air (pp. 959-968). American Society of Mechanical Engineers.

27. Bohn, D., Heuer, T., \& Kusterer, K. (2003, January). Conjugate Flow and Heat Transfer Investigation of a Turbo Charger: Part I-Numerical Results. In ASME Turbo Expo 2003, collocated with the 2003 International Joint Power Generation Conference (pp. 715-722). American Society of Mechanical Engineers.

28. Rehman, F. (2006). Transient conjugate heat transfer analysis of a turbine stage using CFD. AIAA, 32, 5-8.

29. Heuer, T., Engels, B., \& Wollscheid, P. (2005, January). Thermo-mechanical analysis of a turbocharger based on conjugate heat transfer. In ASME Turbo Expo 2005: Power for Land, Sea, and Air (pp. 829-836). American Society of Mechanical Engineers.

30. Olmeda, P., Dolz, V., Arnau, F. J., \& Reyes-Belmonte, M. A. (2013). Determination of heat flows inside turbochargers by means of a one dimensional lumped model. Mathematical and Computer Modelling, 57(7), 1847-1852.

31. Bohn, D., Heuer, T., \& Kusterer, K. (2005). Conjugate flow and heat transfer investigation of a turbo charger. Journal of engineering for gas turbines and power, 127(3), 663-669.

32. Lei, V. M., \& Kawakubo, T. (2007, January). A Fast Method for Conjugate Heat Transfer Analysis of Centrifugal Compressor. In ASME 2007 International Mechanical Engineering Congress and Exposition (pp. 699-706). American Society of Mechanical Engineers.

33. Zheng, X., Jin, L., Du, T., Gan, B., Liu, F., \& Qian, H. (2012). Effect of temperature on the strength of a centrifugal compressor impeller for a turbocharger. Proceedings of the Institution of Mechanical Engineers, Part C: Journal of Mechanical Engineering Science, 0954406212454966.

34. Burke, R. D., Copeland, C. D., Duda, T., \& RayesBelmote, M. A. (2016). Lumped Capacitance and Three-Dimensional Computational Fluid Dynamics Conjugate Heat Transfer Modeling of an Automotive Turbocharger. Journal of Engineering for Gas Turbines and Power, 138(9), 092602.

35. Vieweg, M., \& Pischinger, S. (2017). Numerical Analysis of Energy Flow Paths in Exhaust Gas Turbochargers by Means of Conjugate Heat Transfer. Journal of Engineering for Gas Turbines and Power, 139, 061901-1. 
36. San Andrés, L., Barbarie, V., Bhattacharya, A., \& Gjika, K. (2012). On the Effect of Thermal Energy Transport to the Performance of (Semi) Floating Ring Bearing Systems for Automotive Turbochargers. Journal of Engineering for Gas Turbines and Power, 134(10), 102507.

37. Serrano, J., Tiseira, A., Usaquen, T. R., \& Mijotte, G. (2017). Fast 2-D Heat Transfer Model for Computing Internal Temperatures in Automotive Turbochargers (No. 2017-01-0513). SAE Technical Paper.

38. Serrano, J. R., Olmeda, P., Arnau, F. J., Dombrovsky, A., \& Smith, L. (2015). Analysis and Methodology to Characterize Heat Transfer Phenomena in Automotive Turbochargers. Journal of Engineering for Gas Turbines and Power, 137(2), 021901.

39. Jung, M., Ford, R. G., Glover, K., Collings, N., Christen, U., \& Watts, M. J. (2002). Parameterization and transient validation of a variable geometry turbocharger for mean-value modeling at low and medium speed-load points (No. 2002-01-2729). SAE Technical Paper.

40. Marelli, S., Marmorato, G., \& Capobianco, M. (2016). Evaluation of heat transfer effects in small turbochargers by theoretical model and its experimental validation. Energy, 112, 264-272.

41. Schinnerl, M., Seume, J., Ehrhard, J., \& Bogner, M. (2017). Heat Transfer Correction Methods for Turbocharger Performance Measurements. Journal of Engineering for Gas Turbines and Power, 139(2), 022602.

42. Marelli, S., Gandolfi, S., \& Capobianco, M. (2017). Heat Transfer Effect on Performance Map of a Turbocharger Turbine for Automotive Application (No. 2017-01-1036). SAE Technical Paper.

43. Serrano, J. R., Guardiola, C., Dolz, V., Tiseira, A., \& Cervello, C. (2007).Experimental study of the turbine inlet gas temperature influence on turbocharger performance (No. 2007-01-1559). SAE Technical Paper.

44. Serrano, J., Olmeda, P., Arnau, F., Reyes-Belmonte, M., \& Lefebvre, A. (2013). Importance of heat transfer phenomena in small turbochargers for passenger car applications (No. 2013-01-0576). SAE Technical Paper.

45. Lim, S. M., Dahlkild, A., \& Mihăescu, M. (2016). Wall Treatment Effects on the Heat Transfer in a Radial Turbine Turbocharger. In Proceedings of the 5th International Conference on Jets, Wakes and Separated Flows (ICJWSF2015) (pp. 439-447). Springer International Publishing.

46. Serrano, J. R., Olmeda, P., Arnau, F. J., ReyesBelmonte, M. A., \& Tartoussi, H. (2015). A study on the internal convection in small turbochargers. Proposal of heat transfer convective coefficients. Applied Thermal Engineering, 89, 587-599.

47. Baines, N., Wygant, K. D., \& Dris, A. (2010). The analysis of heat transfer in automotive turbochargers. Journal of Engineering for Gas Turbines and Power,132(4), 042301.
48. Cormerais, M., (2007) Caractérisation expérimentale et modélisation des transferts thermiques au sein d'un turbocompresseur automobile. Application à la simulation du comportement transitoire d'un moteur Diesel à forte puissance spécifique. Thèse de Doctorat de l'Université de Nantes et de l'Ecole Centrale de Nantes, 22 Janvier 2007. 62 Reyes-Belmonte, M.A., (2013), Contribution to the experimental characterization and 1-D modelling of turbochargers for IC engines. Departmento de Maquinas y Motores Termicos. Universitat Politecnica de Valencia, Valencia.

49. Reyes-Belmonte, M.A., (2013), Contribution to the experimental characterization and 1-D modelling of turbochargers for IC engines. Departmento de Maquinas y Motores Termicos. Universitat Politecnica de Valencia, Valencia.

50. Mohd, I. A., Rajoo, S., \& Nordin Darus, A. (2012). HEAT DISTRIBUTION STUDY ON TURBOCHARGER TURBINE'S VOLUTE. Jurnal Mekanikal, 35, 63-81.

51. Shaaban, S., \& Seume, J. R. (2006, May). Analysis of turbocharger non-adiabatic performance. In Institution of Mechanical Engineers: 8th International Conference on Turbochargers and Turbocharging, London, May (pp. 17-18).

52. Burke, R. D., Copeland, C. D., \& Duda, T. (2014, May). Investigation into the assumptions for lumped capacitance modelling of turbocharger heat transfer. In6th International conference on simulation and testing. University of Bath.

53. Kumada, M., Iwata, S., Obata, M., \& Watanabe, O. (1994). Tip clearance effect on heat transfer and leakage flows on the shroud-wall surface in an axial flow turbine. Journal of turbomachinery, 116(1), 39-45.

54. Cormerais, M., Cheese, P., \& Hetet, J-F., (2009, December), Turbocharger Heat Transfer Modeling Under Steady and Transient Conditions, In International Journal of Thermodynamics, vol. 12, no. 4.

55. Aghaali, H. \& Ångström, H-E., (2012), Improving Turbocharged Engine Simulation by Including Heat Transfer in the Turbocharger, In SAE Technical Paper 2012-02-0703.

56. Gallindo, J., Lujan, J.M., Serrano, J.R., Dolz, V., \& Guilain, S. (2006, January), Description of heat transfer model suitable to calculate transient processes of turbocharged diesel engines with one-dimensional gasdynamic codes, In Journal of Applied Thermal Engineering, Vol. 26, Issue 1 (pp 66-76), doi: 10.1016/ j.applthermaleng.2005.04.010.

57. Aghaali, H. \& Ångström, H-E., (2013), Temperature Estimation of Turbocharger Working Fluids and Walls Under Different Engine Loads and Heat Transfer Conditions, In SAE Technical Paper 2013-24-0123.

58. Heuer, T., Engels, B., Klein, A., \& Heger, H. (2006, January). Numerical and experimental analysis of the thermo-mechanical load on turbine wheels of turbochargers. In ASME Turbo Expo 2006: Power for 
Land, Sea, and Air (pp. 325-332). American Society of Mechanical Engineers.

59. Diefenthal, M., Tadesse, H., Rakut, C., Wirsum, M., \& Heuer, T. (2014, June). Experimental and Numerical Investigation of Temperature Fields in a Radial Turbine Wheel. In ASME Turbo Expo 2014: Turbine Technical Conference and Exposition (pp. V01BT24A015V01BT24A015). American Society of Mechanical Engineers.

60. Gu, L., Zemp, A., \& Abhari, R. S. (2014). Numerical study of the heat transfer effect on a centrifugal compressor performance. Proceedings of the Institution of Mechanical Engineers, Part C: Journal of Mechanical Engineering Science, 0954406214557687.

61. Ahdad, F., Groskreutz, M., \& Wang, H. (2007, January). TMF Design Optimisation for Automotive Turbochargers Turbine Housings. In ASME Turbo Expo 2007: Power for Land, Sea, and Air (pp. 551557). American Society of Mechanical Engineers.

62. Hellström, F., \& Fuchs, L. (2010). Assessment of Heat Transfer Effects on the Performance of a Radial Turbine using Large Eddy Simulation. In IMechE, 9th Conference on turbochargers and turbocharging.

63. Bet, F., \& Seider, G. (2011). Thermal Management of a Turbocharger for Unsteady Operation. In STAR European Conference (pp. 22-23).

64. Mamat, A. M., Romagnoli, A., \& Martinez-Botas, R. F. (2014). Characterisation of a low pressure turbine for turbocompounding applications in a heavily downsized mild-hybrid gasoline engine. Energy, 64, 3-16.

65. Mamat, A. B., Martinez-Botas, R. F., Rajoo, S., Romagnoli, A., \& Petrovic, S. (2015). Waste heat recovery using a novel high performance low pressure turbine for electric turbocompounding in downsized gasoline engines: Experimental and computational analysis. Energy, 90, 218-234.

66. Terdich, N., Martinez-Botas, R. F., Romagnoli, A., \& Pesiridis, A. (2014). Mild Hybridization via Electrification of the Air System: Electrically Assisted and Variable Geometry Turbocharging Impact on an Off-Road Diesel Engine.Journal of Engineering for Gas Turbines and Power, 136(3), 031703.

67. Cormerais, M., Hetet, J. F., Chesse, P., \& Maiboom, A. (2005). Heat transfer analysis of a variable geometry turbine under steady and transient conditions. In International Conference on Recent Advances in mechanical \& Materials Engineering (ICRAMME), Kuala Lumpur (Malaysia) May (pp. 30-31).

68. Serrano, J., Olmeda, P., Arnau, F., \& Dombrovsky, A. (2014). General Procedure for the Determination of Heat Transfer Properties in Small Automotive Turbochargers (No. 2014-01-2857). SAE Technical Paper. 
Appendix A. Heat Transfer Modeling Work by Different Researchers

\begin{tabular}{|c|c|c|c|c|c|c|c|}
\hline No. & Reference & Model type & Focus & Analysis type & Assumptions & Equations & Prediction and recommendation \\
\hline 1. & Olmeda et al. & $\begin{array}{l}\text { 1-D lumped } \\
\text { model }\end{array}$ & $\begin{array}{l}\text { Prediction of } \\
\text { turbocharger } \\
\text { outlet properties } \\
\text { and heat flux }\end{array}$ & Steady & $\begin{array}{l}\text { 1. Radial temperature } \\
\text { distribution is negligible } \\
\text { 2. No external heat transfer } \\
\text { 3. No radiation } \\
\text { 4. Turbine side - Heat transfer } \\
\text { Occurs only before expansion } \\
\text { 5. Compressor side -Heat } \\
\text { Transfer occurs only after } \\
\text { compression }\end{array}$ & $\begin{array}{l}\text { Convection: Sieder - Tate: } \\
(h \cdot A)_{l / i} k \cdot a \cdot \operatorname{Re}^{m} \cdot \operatorname{Pr}^{n} \cdot\left(\frac{\mu}{\mu_{0}}\right)^{0} \\
\text { Mechanical power: } \\
\left(m \cdot \dot{C}_{p} \cdot \Delta t\right)_{o i l}+Q_{H 1 / H 2}+Q_{H 2 / H 3} \\
\text { lumped model in matrix form: } \\
K=(h \cdot A)_{i / f l u i d} \quad K_{i / j}\end{array}$ & $\begin{array}{l}\text { Predicted TOT }-<2 \% \\
\text { Predicted COT }-<1 \%\end{array}$ \\
\hline \multirow[t]{4}{*}{2.} & \multirow[t]{4}{*}{ Serrano et al. } & $\begin{array}{l}\text { 1-D lumped } \\
\text { model }\end{array}$ & $\begin{array}{l}\text { 1. Water cooled } \\
\text { and Non-water } \\
\text { cooled } \\
\text { turbocharger } \\
\text { 2. Prediction of } \\
\text { Pulsatile flow } \\
\text { properties } \\
\text { Using HTM. }\end{array}$ & $\begin{array}{l}\text { Steady and } \\
\text { Transient }\end{array}$ & $\begin{array}{l}\text { 1. Radial temperature } \\
\text { Distribution is negligible } \\
2 . \text { Heat transfer is followed } \\
\text { by Work transfer }\end{array}$ & $\begin{array}{l}\text { Conductive conductance: Fourier's law : } \\
\dot{Q}_{i j}^{\text {cond }}=K_{i j} \cdot\left(T_{i}-T_{j}\right) \\
\text { Convective conductance: Newton's law of cooling } \\
: \dot{Q}_{l i}^{\text {conv }}=K_{l i} .\left(T_{i}-T_{j}\right) \\
\text { Energy balance : } \\
\left(K+h A+\frac{1}{\Delta t} C\right) T_{i}^{t+\Delta t}=Q+\frac{1}{\Delta t} C \cdot T_{i}^{t}+h A \cdot T_{i}^{t+\Delta t}\end{array}$ & $\begin{array}{l}\text { 1. Water- cooled turbocharger: } \\
\text { Predicted TOT } - \pm 10^{\circ} \mathrm{C} \\
\text { 2. Non-water-cooled turbocharger: } \\
\text { Predicted TOT }- \text { almost zero deviation } \\
\text { Predicted COT } - \pm 5^{\circ} \mathrm{C} \\
\text { Importance of } \mathrm{HTM} \text { is more noticeable in } \\
\text { Non-water cooled turbocharger } \\
\text { 3. Modeled enthalpy drop is less than } \\
\text { measured enthalpy drop } \\
\text { 4. Prediction of properties at pulsatile } \\
\text { condition is better with HTM }\end{array}$ \\
\hline & & $\begin{array}{l}\text { 1-D lumped } \\
\text { model }\end{array}$ & $\begin{array}{l}\text { Influence of HT in } \\
\text { full load } \\
\text { Engine model - } \\
\text { Turbine model - } \\
\text { Compressor } \\
\text { model }\end{array}$ & Steady & - & - & $\begin{array}{l}\text { 1. Hot map - HT/ML }=\text { Adiabatic map } \\
\text { 2. Adiabatic map }+\mathrm{HT} / \mathrm{ML}=\text { Diabatic } \\
\text { map } \\
\text { 3. Better prediction of COT and TOT } \\
\text { with HTM }\end{array}$ \\
\hline & & $\begin{array}{l}\text { 1-D lumped } \\
\text { model }\end{array}$ & $\begin{array}{c}\text { Advantage of } \\
\text { HTM over LUM }\end{array}$ & $\begin{array}{c}\text { Steady and } \\
\text { Transient }\end{array}$ & $\begin{array}{l}\text { Radial temperature distribution } \\
\text { is negligible }\end{array}$ & $\begin{array}{l}\text { Transient energy balance: } \\
m_{i} c_{i} \cdot \frac{d T_{i}}{d t}=c_{i} \cdot \frac{d T_{i}}{d t}=\sum K_{i j} \cdot\left(T_{i}-T_{j}\right)\end{array}$ & $\begin{array}{l}\text { 1. Predicted Speed: For LUM }=<0.5 \% \\
\text { to } 2 \% \text { For HTM }= \pm 1 \% \text {. } \\
\text { 2. Predicted TOT - improvement of } \\
\text { 20-30K compared to LUM } \\
\text { 3. Predicted COT - same accuracy for } \\
\text { HTM and LUM }\end{array}$ \\
\hline & & $\begin{array}{ll}\text { 1-D } & \text { HT } \\
\text { model } & \end{array}$ & $\begin{array}{c}\text { General } \\
\text { correlation of } \\
\text { HT modeling }\end{array}$ & Steady & $\begin{array}{l}\text { Radial temperature distribution } \\
\text { is negligible }\end{array}$ & $\begin{array}{c}\text { Capacitance }: \\
\text { Turbine: } C_{T}=\alpha \cdot m_{T} \cdot c_{T} \\
\text { Compressor }: C_{c}=\varepsilon \cdot m_{c} \cdot c_{c} \\
\text { Forced convection: } N u=a \cdot P r^{b} \cdot R e^{c} \\
\text { Radiation between nodes } \\
: q_{r}=\frac{\sigma \cdot\left(T_{i}^{4}-T_{j}^{4}\right)}{\frac{1-\varepsilon_{i}}{A_{i} \cdot \varepsilon_{i}}+\frac{1}{A_{i} \cdot F_{i \rightarrow j}}+\frac{1-\varepsilon_{j}}{A_{j} \cdot \varepsilon_{j}}}\end{array}$ & $\begin{array}{l}\text { 1.Predicted COT } - \pm 5^{\circ} \mathrm{C} \\
\text { 2. Predicted TOT - improvement of over } \\
15^{\circ} \mathrm{C}\end{array}$ \\
\hline
\end{tabular}




\begin{tabular}{|c|c|c|c|c|c|c|c|}
\hline 3. & Westin et al. & $\begin{array}{l}\text { 1-D lumped } \\
\text { model }\end{array}$ & $\begin{array}{l}\text { Study of heat loss } \\
\text { from turbine. } \\
\text { Engine model - } \\
\text { Turbine model }\end{array}$ & Steady & $\begin{array}{l}\text { 1. No radiation from Bearing } \\
\text { housing }\end{array}$ & $\begin{array}{l}\text { Radiation : Stafan - Boltzman's law - } \\
\dot{Q}_{\text {rad }}=\epsilon \cdot \sigma \cdot A_{\text {turb,surf }} \cdot T_{\text {turb,surf }}^{4} \\
\text { Conduction }: \text { Fourier's law: } \dot{Q}=K_{\text {cond }} \cdot \Delta T \\
\text { Convection: Newton's law of cooling: } \dot{Q}=a \cdot \Delta T \\
\text { Heat transport between components : } \\
a . \Delta T_{\text {env }}+K_{\text {cond } / b} \cdot \Delta T_{b}+K_{\text {cond } / m} \cdot \Delta T_{m}= \\
\text { c. } m_{\text {turb }}\left(\frac{d T}{d t}\right)_{\text {turb }}\end{array}$ & $\begin{array}{l}\text { 1. Without HTM, when heat loss is not } \\
\text { considered -TOT prediction is }>50 \mathrm{~K} \\
\text { compared to HTM. } \\
2 \text {. Heat loss necessary to predict TOT is } \\
35 \%, 28 \%, 8 \% \text { at } 1600 \mathrm{rpm}, 1800 \mathrm{rpm} \\
\text { and } 1900 \mathrm{rpm} \text { respectively }\end{array}$ \\
\hline 4. & Cormerais et al & $\begin{array}{l}\text { 1-D HT } \\
\text { model }\end{array}$ & $\begin{array}{l}\text { Heat transfer } \\
\text { under steady and } \\
\text { transient analysis }\end{array}$ & $\begin{array}{l}\text { Steady and } \\
\text { Transient }\end{array}$ & $\begin{array}{l}\text { Modeled as combination } \\
\text { of Volumes and nozzles. }\end{array}$ & $\begin{array}{l}\text { Forced convection: Nusselt number: } \\
N u=0.023 . P r^{0.3} \cdot R e^{0.8} \\
\text { Free convection: Nusselt number: } \\
N u=0.53 \text {. }(\mathrm{Gr} . \mathrm{Pr})^{0.25} \\
\text { Heat transfer is calculated from energy balance : } \\
\frac{d T}{d t}= \\
\frac{h_{\text {int }} S_{\text {cint }}\left(T_{f}-T\right)+h_{\text {ext }} S_{\text {cext }}\left(T_{0}-T\right)+\epsilon \sigma\left(T_{0}^{4}-T^{4}\right)}{M . C}\end{array}$ & $\begin{array}{l}\text { 1. Transient exit temperature } \\
\text { 2. Flow map } \\
\text { 3. Turbine power and HT }\end{array}$ \\
\hline \multirow[t]{3}{*}{5.} & \multirow[t]{3}{*}{ Burke et al. } & $\begin{array}{l}\text { 1-D HT } \\
\text { model }\end{array}$ & $\begin{array}{l}\text { Study of heat } \\
\text { addition before } \\
\text { compression }\end{array}$ & Steady & $\begin{array}{l}\text { 1. Conduction within the } \\
\text { Housing is negligible } \\
\text { 2. Heat is added only before and } \\
\text { after compression. }\end{array}$ & $\begin{array}{l}\text { Total Convective heat transfer : } Q_{\text {Total }}= \\
Q_{b}+Q_{a}=h_{b} h_{b}\left(T_{1}-T_{c}\right)+h_{a} A_{a}\left(T_{2^{\prime}}-T_{c}\right) \\
\text { Convection: Sieder-Tate: } \\
(h \cdot A)_{l / i}=a \cdot \operatorname{Re}_{d}^{a_{2}} \cdot \operatorname{Pr}^{a_{3}} \cdot\left(\frac{\mu_{\text {bulk }}}{\mu_{\text {skin }}}\right)^{a_{4}} \\
\text { Compressor exposed area: Internal area: } \\
A_{T}=A_{b}+A_{a}=\alpha_{A} A_{T}+\left(1-\alpha_{A}\right) A_{T}\end{array}$ & $\begin{array}{l}\text { 1. When exposed area } \alpha_{A}=0 \text {, compressor } \\
\text { efficiency is overestimated. For, } \propto_{A}>0 \text {, } \\
\text { compressor efficiency is underestimated } \\
\text { 2. Prediction of apparent efficiency and } \\
\text { COT Recommendation: } \\
\text { Division of thermal node of compressor } \\
\text { into two - compressor front face and rest } \\
\text { of compressor. }\end{array}$ \\
\hline & & $\begin{array}{l}\text { 1-D lumped } \\
\text { model }\end{array}$ & $\begin{array}{l}\text { On-engine HT } \\
\text { analysis }\end{array}$ & $\begin{array}{c}\text { Steady and } \\
\text { transient }\end{array}$ & $\begin{array}{l}\text { 1. Radial temperature } \\
\text { distribution is negligible } \\
\text { 2. Turbine side -Heat transfer } \\
\text { occurs only before expansion } \\
\text { 3. Compressor side- Heat } \\
\text { transfer occurs only after } \\
\text { compression }\end{array}$ & $\begin{array}{c}\text { Conductive conductance: Fourier's law: } \\
\dot{Q}_{i j}^{\text {cond }}=K_{i j} .\left(T_{i}-T_{j}\right) \\
\text { Convective conductance: Newton's law of cooling : } \\
\dot{Q}_{l i}^{\text {conv }}=K_{l i} .\left(T_{i}-T_{j}\right)\end{array}$ & $\begin{array}{l}\text { 1. Predicted TOT - } \\
\text { Steady state: improvement from } 29^{\circ} \mathrm{C} \\
\text { to } 13^{\circ} \mathrm{C} \\
\text { Transient state: improvement from } \\
35^{\circ} \mathrm{C} \text { to } 14^{\circ} \mathrm{C} \\
\text { 2. Predicted Metal temperature: } \\
\text { Compressor housing - within } 17^{\circ} \mathrm{C} \\
\text { Turbine housing - within } 15^{\circ} \mathrm{C}\end{array}$ \\
\hline & & $\begin{array}{l}\text { 1-D HT } \\
\text { model }\end{array}$ & $\begin{array}{l}\text { HT between } \\
\text { exhaust gas and } \\
\text { turbine node }\end{array}$ & $\begin{array}{c}\text { Steady, } \\
\text { pulsating and } \\
\text { transient }\end{array}$ & $\begin{array}{l}\text { 1. Work and heat transfer } \\
\text { occurs independently } \\
\text { 2. Heat transfer occurs is only } \\
\text { before and after compression / } \\
\text { expansion } \\
\text { 3. Diffuser }- \text { constant diameter } \\
\text { pipe, Tongue - constant diameter } \\
\text { short pipe, Turbine - Two pipes of } \\
\text { constant diameter }\end{array}$ & $\begin{array}{c}\text { Energy balance: } m_{T} C_{p, T} \frac{d T_{T}}{d t}= \\
Q_{b, T}+Q_{a, T}-Q_{T / B}-Q_{T \cdot r a d}-Q_{T, c o n v} \\
\text { Convection: Sieder-Tate: } \\
N u=c_{1} \cdot \operatorname{Re}_{t}^{c_{2}} \cdot \operatorname{Pr}^{1 / 3} \cdot\left(\frac{\mu_{b u l k}}{\mu_{\text {skin }}}\right)^{0.14}\end{array}$ & $\begin{array}{c}\text { Transient: } \\
\text { Predicted TOT - improvement from } \\
33^{\circ} \mathrm{C} \text { to }-3^{\circ} \mathrm{C}\end{array}$ \\
\hline
\end{tabular}




\begin{tabular}{|c|c|c|c|c|c|c|c|}
\hline 6. & Baines et al. & $\begin{array}{l}\text { HT network } \\
\text { model }\end{array}$ & $\begin{array}{l}\text { Heat transfer } \\
\text { analysis }\end{array}$ & Steady & $\begin{array}{l}\text { 1. Constant ambient } \\
\text { temperature } \\
\text { 2. In internal heat transfer, } \\
\text { radiation is neglected. }\end{array}$ & $\begin{array}{c}\text { External heat transfer } \\
Q_{\text {ext }}=Q_{\text {conv }}+Q_{\text {rad }}+Q_{\text {cond }} \\
=\bar{h}_{S} A_{s}\left(T_{s}-T_{a}\right)+\kappa A_{c}\left(T_{s}-T_{a}\right) / x+\epsilon \sigma\left(T_{s}^{4}-T_{a}^{4}\right) \\
\text { Surface temperature: Forced convection: } \\
N u=a \cdot \operatorname{Pr}^{b} \cdot \operatorname{Re}^{c} \\
\text { Free convection }: N u=d \cdot \operatorname{Pr}^{f} \cdot G r^{e} \\
\text { Conservation of energy: } \\
m_{\text {oil }}\left(h_{\text {ooil,out }}-h_{\text {ooil,in }}\right)= \\
P_{T}-P_{C}+Q_{T, \text { int }}-Q_{C, \text { int }}-Q_{\text {Bext }}\end{array}$ & $\begin{array}{c}\text { Prediction of compressor and turbine } \\
\text { external and internal heat transfer with } \\
\text { good accuracy }\end{array}$ \\
\hline 7. & $\begin{array}{l}\text { Romagnoli and } \\
\text { Martinez-Botas }\end{array}$ & $\begin{array}{l}\text { 1-D lumped } \\
\text { model }\end{array}$ & $\begin{array}{l}\text { On-engine HT } \\
\text { analysis }\end{array}$ & Steady & $\begin{array}{l}\text { 1. Heat is added only before and } \\
\text { after compression. } \\
\text { 2. Uniform wall thickness } \\
\text { 3. Compressor, Turbine and } \\
\text { Bearing housing are modeled as } \\
\text { simple cylinder. }\end{array}$ & 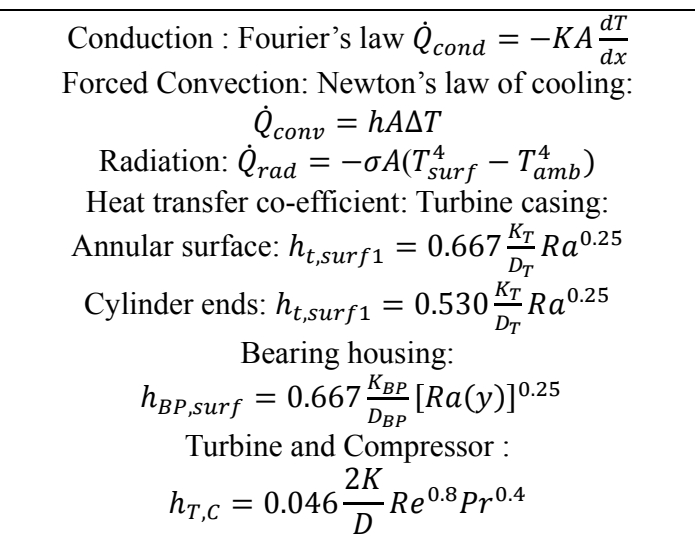 & $\begin{array}{l}\text { 1. Predicted COT - maximum deviation } \\
\text { is } 5 \mathrm{~K} \\
\text { 2. Predicted Diabatic efficiency } \\
\eta_{\text {dia }}-<3 \% 3 \text {. } \\
\text { 3. Predicted Heat conducted - } \Delta \mathrm{Q} \\
\text { average deviation - } \pm 8 \%\end{array}$ \\
\hline
\end{tabular}

